\title{
A MURINE STAPHYLOCOCCUS AUREUS FRACTURE-RELATED INFECTION MODEL CHARACTERISED BY FRACTURE NON-UNION, STAPHYLOCOCCAL ABSCESS COMMUNITIES AND MYELOID- DERIVED SUPPRESSOR CELLS
}

\author{
M.I. Hofstee ${ }^{1,2}$, M. Riool ${ }^{2}$, F. Gieling ${ }^{1}$, V. Stenger ${ }^{1}$, C. Constant ${ }^{1}$, D. Nehrbass ${ }^{1}$, S. Zeiter ${ }^{1}$, R.G. Richards ${ }^{1}$, \\ S.A.J. Zaat ${ }^{2}$ and T.F. Moriarty ${ }^{1, *}$ \\ ${ }^{1} \mathrm{AO}$ Research Institute Davos, Davos Platz, Switzerland \\ ${ }^{2}$ Amsterdam UMC, University of Amsterdam, Department of Medical Microbiology and Infection \\ Prevention, Amsterdam Institute for Infection and Immunity, Amsterdam, the Netherlands
}

\begin{abstract}
A fracture-related infection (FRI) is a serious complication that can occur after surgical fixation of bone fractures. Affected patients may encounter delayed healing and functional limitations. Although it is well established that Staphylococcus aureus (S. aureus) is the main causative pathogen of an FRI, the pathophysiology of an S. aureus-induced FRI is not well characterised over time. Therefore, an experimental study in mice comparing S. aureus-inoculated and non-inoculated groups was performed that particularly focused on staphylococcal abscess communities (SACs) and host cellular response.

$\mathrm{C} 57 \mathrm{Bl} / 6 \mathrm{~N}$ female mice received a double osteotomy of the femur, which was stabilised using a titanium 6-hole MouseFix locking plate and four screws. Animals were either S. aureus-inoculated or non-inoculated and euthanised between 1 and $28 \mathrm{~d}$ post-surgery. Histopathological evaluation showed normal bone healing for non-inoculated mice, whereas inoculated mice had no fracture consolidation and severe osteolysis. Within the bone marrow of inoculated mice, SACs were observed from $7 \mathrm{~d}$, which increased in size and number over time. A fibrin pseudocapsule enclosed the SACs, which were surrounded by many Ly6G+ neutrophils with some Ly $6 \mathrm{C}^{+}$monocytes and $\mathrm{F} 4 / 80^{+}$macrophages, the majority of which were viable. The abscesses were encapsulated by fibrin(ogen), collagen and myofibroblasts, with regulatory $\mathrm{T}$ cells and M2 macrophages at the periphery. Only bone marrow monocytes and neutrophils of inoculated mice displayed functional suppression of T cells, indicative of myeloid-derived suppressor cells.

The present study revealed that an FRI in mice is persistent over time and associated with osteolysis, SAC formation and an immunosuppressive environment.
\end{abstract}

Keywords: Staphylococcus aureus, fracture-related infection, staphylococcal abscess community, myeloidderived suppressor cell, immunosuppression.

*Address for correspondence: Thomas Fintan Moriarty, PhD, AO Research Institute Davos, Clavadelerstrasse 8, 7270 Davos, Switzerland.

Telephone number: +41 814142397 E-mail: fintan.moriarty@aofoundation.org

Copyright policy: This article is distributed in accordance with Creative Commons Attribution Licence (http://creativecommons.org/licenses/by-sa/4.0/).

\begin{tabular}{|c|c|c|c|}
\hline \multirow{5}{*}{ AAALAC } & List of Abbreviations & ClfA & clumping factor A \\
\hline & & Coa & coagulase \\
\hline & Association for Assessment and & DAPI & 4',6-diamidino-2-phenylindole \\
\hline & Accreditation for Laboratory Animal & Eap & extracellular adherence protein \\
\hline & Care & EDTA & ethylenediaminetetraacetic acid \\
\hline ANOVA & analysis of variance & Emp & extracellular matrix protein \\
\hline $\mathrm{APC}$ & allophycocyanin & FACS & fluorescence-activated cell sorting \\
\hline Arg-1 & arginase-1 & FBS & foetal bovine serum \\
\hline $\mathrm{BB}$ & Brown and Brenn & FITC & fluoresein isothiocyanate \\
\hline CCOS & culture collection of Switzerland & FOXP3 & forkhead box P3 \\
\hline CD & cluster of differentiation & FRI & fracture-related infection \\
\hline CFU & colony forming unit & G\&E & giemsa and eosin \\
\hline
\end{tabular}


HBSS

H\&E

HOES

IL

iNOS

Ly6

MDSC

MMA

NO

PBS

PBS-T

PE

PGE2

PJI

PMN

rIL-2

ROS

RPMI

RT

S. aureus

SAC

SPF

TGF- $\beta$

TLR

Treg

TSB

TUNEL

vWbp

$\alpha \mathrm{SMA}$
Hank's buffered salt solution

haematoxylin and eosin

histopathological osteomyelitis evaluation score

interleukin

inducible nitric oxide synthase

lymphocyte antigen 6

myeloid-derived suppressor cell

methyl methacrylate

nitric oxide

phosphate-buffered saline

PBS Tween 20

phycoerythrin

prostaglandin E2

prosthetic joint infection

polymorphonuclear cell

recombinant IL-2

reactive oxygen species

Roswell Park Memorial Institute

room temperature

Staphylococcus aureus

staphylococcal abscess community

specific-pathogen free

transforming growth factor beta

toll-like receptor

regulatory $\mathrm{T}$ cell

tryptic soy broth

terminal deoxynucleotidyl

transferase dUTP nick end labelling

von Willebrand factor-binding

protein

alpha smooth muscle actin

\section{Introduction}

FRIs are one of the most serious complications associated with the surgical fixation of bone fractures. The rate of FRIs in closed fractures ranges between 1-2 \%, whereas it can reach up to $30 \%$ for open fractures (Trampuz and Zimmerli, 2006). S. aureus is the predominant causative pathogen in an FRI, causing approximately $30 \%$ of cases (Trampuz and Zimmerli, 2006). Unfortunately, treatment efforts fail in 4 to $11 \%$ of cases, leading to further surgical revisions, lifelong suppression therapy or even amputation of the affected limb (Bezstarosti et al., 2019; Bose et al., 2015; Huh et al., 2011; Kanakaris et al., 2014). When specifically examining failure rates for FRI patients treated with implant retention, recurrence of infection varied from 0 to $14 \%$ for patients that had a revision surgery within 3 weeks of infection, 11 to $18 \%$ for patients that had a revision surgery within 3-10 weeks of infection and $33 \%$ for patients that had a revision surgery after 10 weeks of infection (Morgenstern et al., 2021). Although early revision surgery does reduce the risk of recurrent infection, current treatment efforts are not ideal and may need to be combined with different strategies.

Traditionally, an FRI has been classified as acute or chronic based upon time elapsed from initial surgery and symptom onset (Metsemakers et al., 2016). The distinction between acute and chronic FRI is also linked to the pathophysiology and treatment, however, this transition is poorly described in the literature and a clear time-related cut-off has never been scientifically defined (Morgenstern et al., 2021). In the early stages of an acute FRI, the infiltrating immune cells are predominantly PMNs, whilst in a chronic FRI, the local inflammatory cells are predominantly macrophages (Klosterhalfen et al., 1996). A chronic FRI is also associated with osteolysis, sequestrum formation and non-union (Alt et al., 2011; Metsemakers et al., 2016; Ochsner and Hailemariam, 2006).

One recently described feature of the pathophysiology of $S$. aureus infection is the SAC, which has been identified in the renal and peritoneal tissue (Cheng et al., 2009; Cheng et al., 2010; Rauch et al., 2012) and in the bone marrow (Brandt et al., 2018; Farnsworth et al., 2017). SACs form the centre of abscesses and are surrounded by an amorphous pseudocapsule comprised of fibrin deposits (Cheng et al., 2011; Cheng et al., 2010; Thomer et al., 2016b) formed by the action of the $S$. aureus-produced enzymes Coa and vWbp (Bjerketorp et al., 2004; Friedrich et al., 2003; Thomer et al., 2016b). This pseudocapsule appears to serve as a barrier to invasion of immune cells, causing them to accumulate in large numbers at the periphery, leading to the persistence of S. aureus (Brandt et al., 2018; Cheng et al., 2010; Hofstee et al., 2020a; Kobayashi et al., 2015; Thomer et al., 2016b).

Persistence of $S$. aureus has also been linked to MDSCs, which can inhibit proinflammatory responses of monocytes/macrophages, and has been mainly studied in mice (Heim et al., 2015a; Heim et al., 2018; Heim et al., 2015b; Heim et al., 2014; Peng et al., 2017). In mice, monocytic MDSCs are CD11b

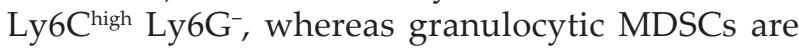
$\mathrm{CD}_{11 b^{+}}$Ly6C $^{\text {low }}$ Ly6G . Regular murine monocytes and neutrophils have the same phenotypical markers as monocytic and granulocytic MDSCs, which makes identifying murine MDSCs with immunohistochemical stains challenging. What sets monocytic and granulocytic MDSCs aside from regular monocytes and neutrophils are their immunosuppressive abilities, which are facilitated by the enzymes iNOS and/or Arg-1 (Ostrand-Rosenberg and Fenselau, 2018; Veglia et al., 2018) and usually proven in functional T cell suppression assays (Bronte et al., 2016). For S. aureus infections, whether MDSCs are distributed amongst the bone marrow or arranged in an organised manner is unknown.

The aim of the present study was to examine SAC formation in a murine FRI model and investigate whether MDSCs were present within bone marrow of these mice and possibly associated with SACs and/or abscess structures. Furthermore, the aim was to identify the host macromolecules associated with SAC formation, including fibrinogen and collagen. A femoral double osteotomy mouse model was 
used where a femoral bone segment was created, which was either not inoculated or inoculated with $S$. aureus, and the femur was stabilised using a titanium 6-hole MouseFix locking plate. Immuno(fluorescent) stainings, HOES (Tiemann et al., 2014) and ex vivo analyses were performed to investigate differences between inoculated and non-inoculated mice, with a particular focus on the maturation of SACs over time and possible immunosuppressive properties of the involved host cells.

\section{Materials and Methods}

\section{Animals}

All animal experiments were approved by the ethical committee of the Canton of Graubünden, Switzerland (approval number 2017_28 and 2019_10) and were carried out in an AALAC International accredited facility. 74 SPF C57Bl/6N female mice (Charles River) 20-28 weeks old at the time of surgery were used. Animals were acclimatised for at least 2 weeks prior to surgical intervention. Mice were divided randomly into $S$. aureus-inoculated and non-inoculated groups. Time points for sacrifice were 1, 3, 7, 14, 21 and $28 \mathrm{~d}$ post-surgery ( $n=6$ per subgroup) for inoculated mice and 3, 14 and $28 \mathrm{~d}$ ( $n=6$ per subgroup) for noninoculated animals used for histological outcome parameters. Mice used for CFU quantification and ex vivo cultures were sacrificed $21 \mathrm{~d}$ post-surgery for both the inoculated group $(n=6)$ and non-inoculated group $(n=6)$. Cages were randomly assigned to the different subgroups. Individual ventilated cages (Techniplast, Schwerzenbach, Switzerland and Allentown, Schlieren, Switzerland) housed 2 to 6 mice each, were under $12 \mathrm{~h}$ light/dark cycle and were enriched with a plastic house, paper as well as wood for gnawing. Both water and food (3436, Provimi Kliba AG, Kaiseraugst, Switzerland) were provided ad libitum.

\section{Bacteria and inoculum preparation}

S. aureus JAR 06.01.31 (CCOS number 890, Wädenswil, Switzerland), obtained from a patient with an orthopaedic device-related infection (Moriarty et al., 2010), was used for inoculum preparation. An overnight culture was prepared the day before surgery by incubating one colony in $50 \mathrm{~mL}$ TSB (Oxoid, Basel, Switzerland) at $37^{\circ} \mathrm{C}$ while shaking. From the overnight culture, a fresh logarithmic phase culture was prepared in TSB. Bacteria were washed twice with PBS (Gibco) $1.5 \mathrm{~h}$ before surgery and diluted in PBS to obtain a $1 \mu \mathrm{L}$ inoculum containing approximately $1 \times 10^{4}$ CFU. $1 \mu$ L sterile PBS was used as control.

\section{Surgery and animal welfare}

Prior to surgery, animals were anaesthetised by induction with sevoflurane $\left(\sim 5 \%\right.$ in $\mathrm{O}_{2}$, flow rate $1 \mathrm{~L} / \mathrm{min}$; Sevofluran Baxter, Baxter AG). During surgery, the anaesthesia was maintained using sevoflurane $\left(\sim 2-3 \%\right.$ in $\mathrm{O}_{2}$, flow rate $\left.0.6-1 \mathrm{~L} / \mathrm{min}\right)$. Intraoperative analgesia consisted of buprenorphine (0.1 mg/kg subcutaneously; Bupaq, Streuli Pharma AG, Uznach, Switzerland) and carprofen (5 mg/ kg subcutaneously; Norocarp, ufamed AG, Sursee, Switzerland) injected immediately after anaesthetic induction. After clipping and aseptically preparing the surgical field, a skin incision was made from the tail base to the left stifle. The subcutaneous fascia lata was cut and the level between the quadriceps and biceps femoris muscle was bluntly dissected. The left femur was stabilised with a titanium 6-hole MouseFix locking plate (RISystems AG, Davos Platz, Switzerland) and 4-outermost screws were inserted. The 2-inner screw-holes were left empty and used to generate 2 osteotomies with the MouseFix Drill\&Saw guide (RISystems) and a Gigly hand saw (RISystems, $0.22 \mathrm{~mm}$ diameter). This created a $2 \mathrm{~mm}$ femoral segment. This segment was taken out and $1 \mu \mathrm{L}$ of either bacterial inoculum or sterile PBS was pipetted on top of the bone marrow of the segment. The inoculum or saline could absorb into the bone for 3 min before the segment was placed back into its original place without fixation. The fascia lata and the skin were closed with continuous sutures (5-0 Vicryl rapide, Ethicon, Courcelles, Belgium). Post-operative analgesia consisted of buprenorphine $(0.1 \mathrm{mg} / \mathrm{kg}$ subcutaneously) every $4-10 \mathrm{~h}$ for $24 \mathrm{~h}$ as well as paracetamol $(1.9 \mathrm{mg} / \mathrm{mL})$ added to the drinking water for $7 \mathrm{~d}$ (DAFALGAN sirup for children, BristolMyers Squibb SA, Steinhausen, Switzerland). Postoperative radiographs were taken to confirm that the osteotomy and plate position were correct and to check for fractures. The mice wellbeing was checked daily by an animal caretaker and scored twice a day until $5 \mathrm{~d}$ post-surgery, followed by daily scoring up to $7 \mathrm{~d}$ and twice per week thereafter. Animals were monitored for their general and eating behaviour and the load they placed on the operated leg. External appearance and wound status were also monitored. Weight was monitored 3 and $7 \mathrm{~d}$ post-surgery and weekly thereafter. Mice were sacrificed by inducing general anaesthesia with sevoflurane followed by cervical dislocation.

\section{Fixation, sectioning and stains}

Some of the left femoral bones $(n=24)$ were fixed in $70 \%$ methanol immediately after euthanasia. The fixed samples were embedded in MMA (SigmaAldrich) with the implant left in place. Sections $(200 \mu \mathrm{m})$ were prepared using a Leica 1600 rotating saw microtome (Leica microsystems), rehydrated with 1-acetoxy-2-methoxyethane and ethanol gradient and stained with $15 \%(\mathrm{v} / \mathrm{v})$ giemsa and $1 \%$ (v/v) eosin (G\&E; both Sigma-Aldrich). Images were taken with an Olympus BX63 brightfield microscope (Olympus).

For paraffin-wax-embedded samples $(n=26)$, left femora were fixed with formalin and subsequently decalcified using $12.5 \%$ (w/v) EDTA (Roth AG) and $1.25 \%(w / v)$ sodium hydroxide (Sigma-Aldrich) 
decalcification solution. Then, implants were removed and the remaining bone and soft tissue was embedded in paraffin wax (Leica microsystems). Paraffin wax sections $(5 \mu \mathrm{m})$ were cut using a paraffin wax HM 355 S microtome (Microm, Thermo Fisher Scientific), dewaxed and rehydrated through a descending ethanol gradient. Sections were either stained with Mayer's haematoxylin and $1 \%(\mathrm{v} / \mathrm{v})$ eosin (H\&E; both Sigma-Aldrich), BB (Brown and Brenn, 1931), TUNEL assay to detect apoptotic cells (Abcam; \#ab206386, manufacturer's protocol was used), picro-Mallory, picro-sirius red or immuno(fluorescent) stains. For more details on the last three stains, see below.

\section{Picro-Mallory trichrome stain}

To allow the acid dyes to stain more intensely, sections were post-fixed with Bouin's fluid [9\% $(\mathrm{v} / \mathrm{v})$ formaldehyde and $5 \%(\mathrm{v} / \mathrm{v})$ acetic acid in water-saturated picric acid $0.9 \%(\mathrm{v} / \mathrm{v})$ ] overnight at RT. Then, sections were rinsed in distilled water to remove the Bouin's fluid. Weigert's iron haematoxylin (Sigma-Aldrich), prepared following the manufacturer's instructions, was applied for $20 \mathrm{~min}$ to stain nuclei and samples were stained with a picro-Mallory trichrome staining following a previously described protocol (Lendrum et al., 1962).

\section{Picro-sirius red stain}

Sections were stained with Weigert's iron haematoxylin for $8 \mathrm{~min}$ and differentiated in lukewarm running tap water. Then, sections were placed into the picro-sirius red solution $[0.1 \%(\mathrm{w} / \mathrm{v})$ sirius red F3B (Sigma-Aldrich) in water-saturated picric acid] for $1 \mathrm{~h}$. Samples were washed twice using $1 \%(\mathrm{v} / \mathrm{v})$ aqueous acidified acid and most of the water was removed by shaking the sections.

\section{Immuno(fluorescent) stains}

An antigen retrieval step was performed by boiling the sections in sodium citrate buffer $(0.1 \mathrm{~mol} / \mathrm{L}, \mathrm{pH} 6.0$; Sigma-Aldrich) for $15 \mathrm{~min}$. Endogenous peroxidase was blocked by incubation for $30 \mathrm{~min}$ in methanol containing hydrogen peroxide $\left[0.3 \%(\mathrm{v} / \mathrm{v}) \mathrm{H}_{2} \mathrm{O}_{2}\right.$ in absolute methanol] for samples subsequently stained with a peroxidase-linked antibody. Samples stained with fluorescently labelled secondary antibodies were incubated for $5 \mathrm{~min}$ in absolute methanol. Sections were washed twice in PBS with $0.1 \%(\mathrm{v} / \mathrm{v})$ Tween 20 (PBS-T; both Sigma-Aldrich) and blocked by incubation with $5 \%(\mathrm{v} / \mathrm{v})$ animal-free blocker (Vector Laboratories, Burlingame, CA, USA) in PBS-T for $1 \mathrm{~h}$ at RT in a moist chamber. Blocking buffer was removed and sections were incubated overnight at $4{ }^{\circ} \mathrm{C}$ with primary antibodies in PBS-T with $0.5 \%$ (v/v) animal-free blocker. Primary antibodies were omitted for negative control sections. See Table 1 for the different primary antibody combinations, concentrations, targets and matching secondary antibodies. Secondary antibodies were applied after overnight incubation with the primary antibodies.
Samples were washed three times with PBS-T before each incubation step. All secondary antibodies were diluted 1 : 200 in PBS-T with $0.5 \%$ (v/v) animal-free blocker and were incubated for $30 \mathrm{~min}$ at RT in the dark. Lastly, sections were incubated with Trueview and coverslipped using Vectashield vibrance antifading mounting medium with DAPI (both Vector Laboratories) according to manufacturer's instructions (Table 1; staining 1-7). Alternatively, samples were incubated with $\mathrm{ABC}$ complex and ImmPACT DAB solution (both Vector Laboratories) following the manufacturer's instructions and counterstained with Mayer's haematoxylin (Table 1; staining 8).

Non-fluorescently stained paraffin wax samples were mounted using Eukitt mounting medium (Sigma-Aldrich) and imaged using an Olympus BX63 microscope. Immunofluorescently-stained samples were examined using a Zeiss LSM 800 inverse fluorescence microscope and image processing was performed using the ZEN (blue edition) software (Zeiss).

\section{Histopathological osteomyelitis evaluation score} G\&E-stained MMA-embedded femora $(n=2$ or 3) with an inoculated or non-inoculated bone segment were evaluated by a pathologist using the HOES (Tiemann et al., 2014). This score evaluates three acute osteomyelitis features (A1-3) and two chronic osteomyelitis features (C1-2). Osseonecrosis (A1), soft tissue necrosis (A2) and granulocyte infiltration (A3) were scored as indicators of acute osteomyelitis, whereas bone neogenesis/fibrosis (C1) and lymphocyte/macrophage infiltration (C2) were evaluated as features of chronic osteomyelitis. The 5 above mentioned parameters were scored from 0 to 5 (Table 2).

\section{SAC size}

Images of SACs in paraffin-wax- or MMA-embedded samples were taken using the Zeiss Axio Vert.A1 microscope (Zeiss). SAC number was determined for one section per mice and SAC size was established by measuring horizontal and vertical length of SACs with the measuring tool from the AxioVision SE64 software (Zeiss) and calculating the surface area (in $\mathrm{mm}^{2}$ ) of the SACs.

\section{Bone marrow cell sorting}

Soft tissue and implants were removed from the operated femora of inoculated $(n=5)$ and non-inoculated mice $(n=5)$ and used for CFU quantification. The outer ends of the femoral bones were cut off and bone marrow cells were flushed out using a $24 \mathrm{G} \times 1$ needle attached to a $2 \mathrm{~mL}$ syringe containing HBSS (Gibco). The collected cells were passed through a $70 \mu \mathrm{m}$ cell strainer and centrifuged at $300 \times g$ for $6 \mathrm{~min}$ at $4^{\circ} \mathrm{C}$. Bone marrow supernatant was collected for CFU quantification and the cell pellet was incubated with $5 \mathrm{~mL}$ red blood cell lysis buffer $\left[15 \mathrm{mmol} / \mathrm{L} \mathrm{NH}_{4} \mathrm{Cl}, 1 \mu \mathrm{mol} / \mathrm{L} \mathrm{KHCO}_{3}\right.$ (both 


\begin{tabular}{|c|c|c|c|c|c|c|c|c|}
\hline 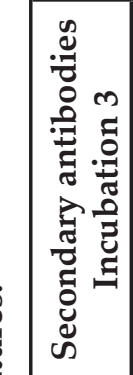 & 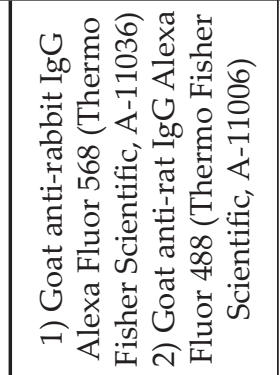 & & 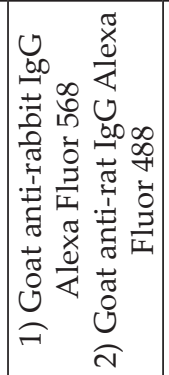 & & & & & \\
\hline 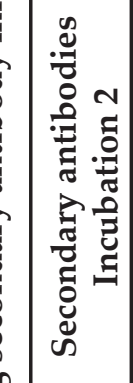 & 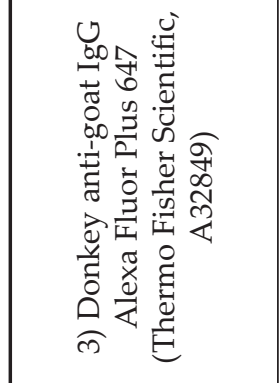 & 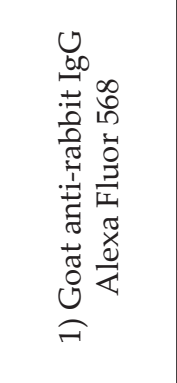 & 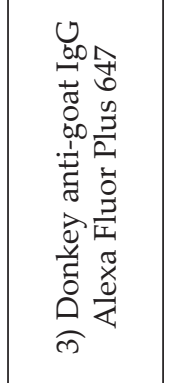 & & 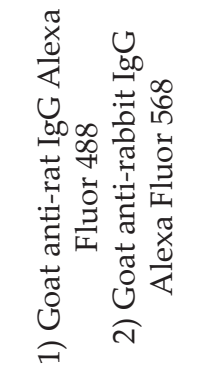 & 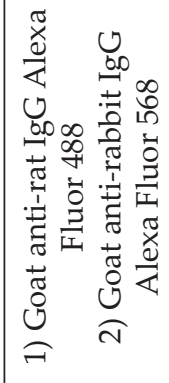 & 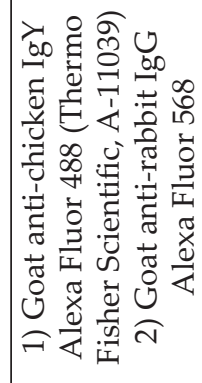 & \\
\hline 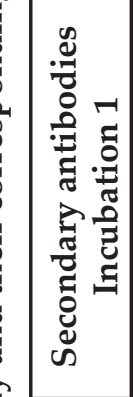 & 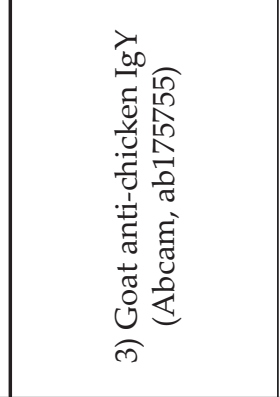 & 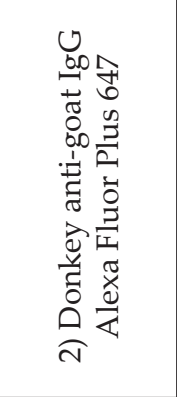 & 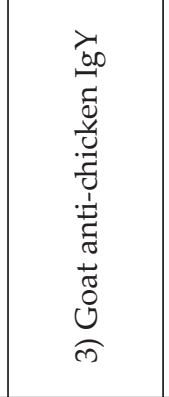 & 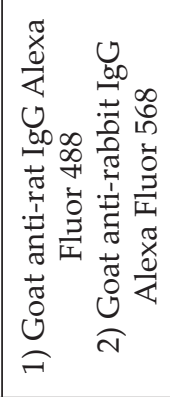 & 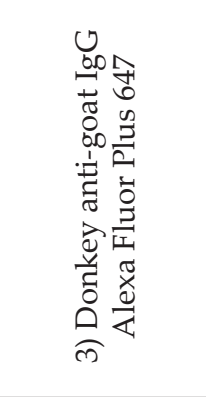 & 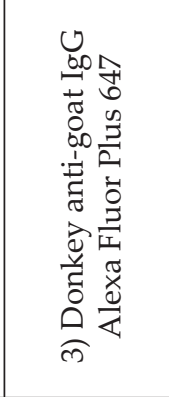 & 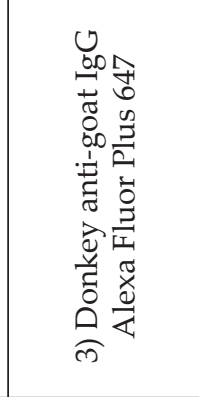 & 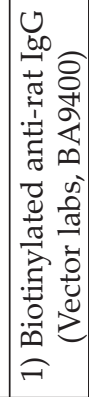 \\
\hline 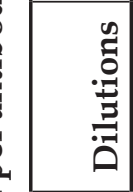 & 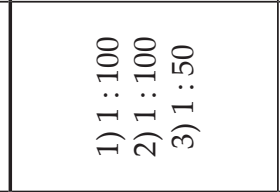 & 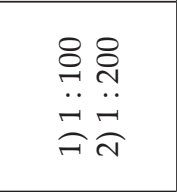 & 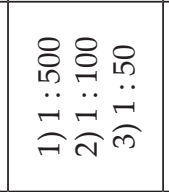 & 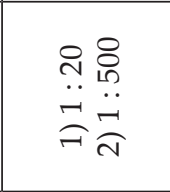 & 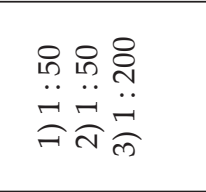 & 오용 & 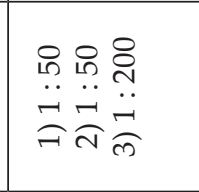 & $\stackrel{\stackrel{\circ}{n}}{\stackrel{\leftrightarrow}{-}}$ \\
\hline 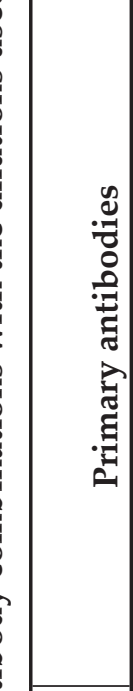 & 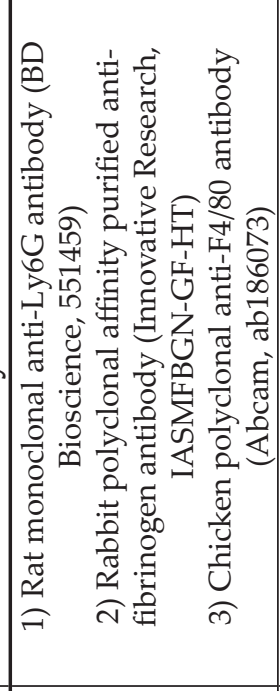 & 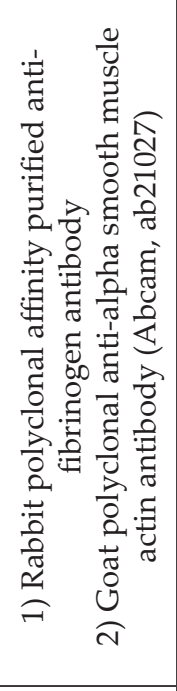 & 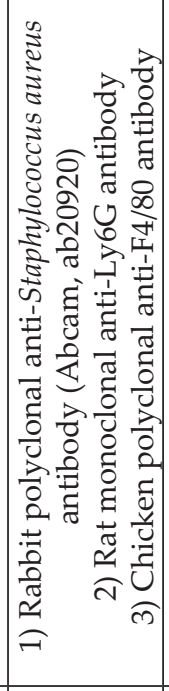 & 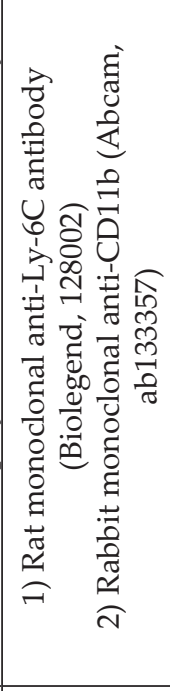 & 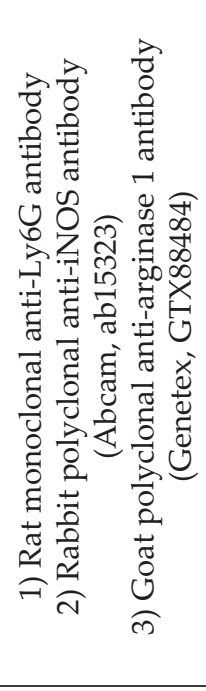 & 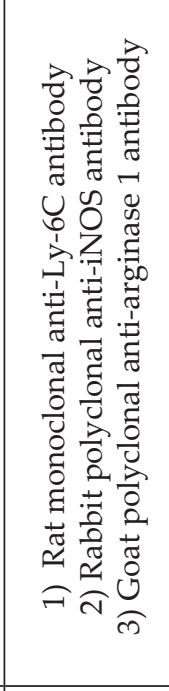 & 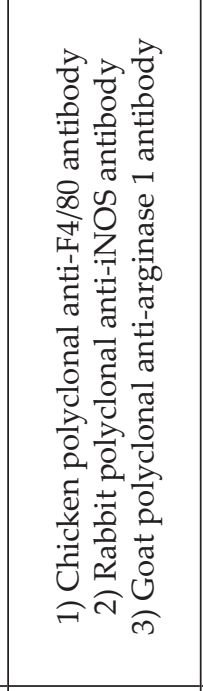 & 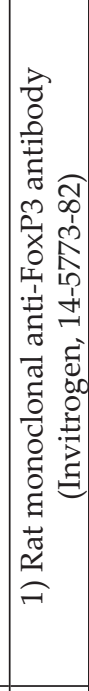 \\
\hline 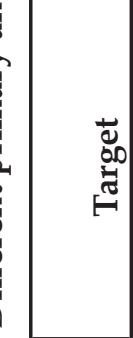 & 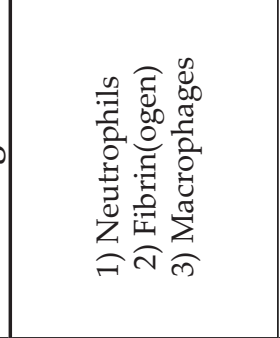 & 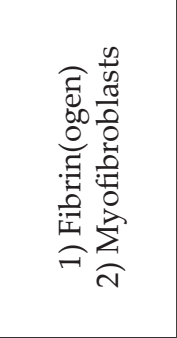 & 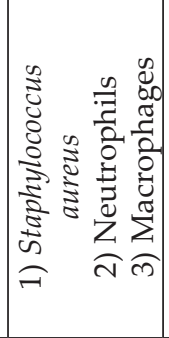 & 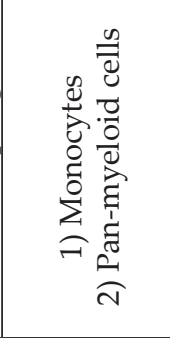 & 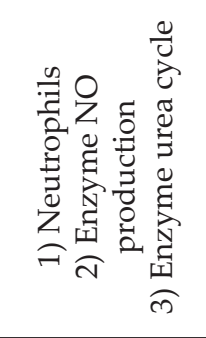 & 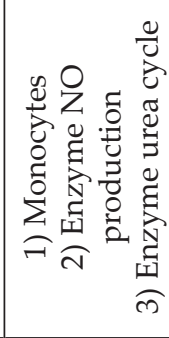 & 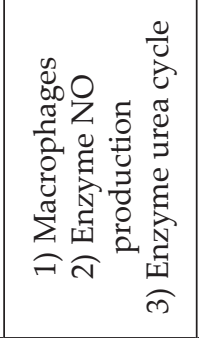 & 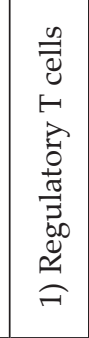 \\
\hline $\begin{array}{l}: \\
\text { के }\end{array}$ & $r$ & $N$ & $m$ & 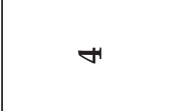 & in & 0 & $\Lambda$ & $\infty$ \\
\hline
\end{tabular}


Table 2. Severity scores used to score the five different acute and chronic osteomyelitis markers of the HOES.

\begin{tabular}{|c|c|}
\hline Severity score & Description \\
\hline 0 & A feature was absent in the tissue \\
\hline 1 & A feature was slightly noticeable within the tissue \\
\hline 2 & A feature was focally present in the tissue \\
\hline 3 & A feature was multi-focally present in the tissue \\
\hline 4 & A feature was more than $50 \%$ present in the tissue \\
\hline 5 & The whole tissue was affected by a feature \\
\hline
\end{tabular}

Sigma-Aldrich) and $10 \mu \mathrm{mol} / \mathrm{L}$ EDTA] for $5 \mathrm{~min}$ at RT. Next, 25 mL RPMI (Gibco) medium supplemented with $3 \%(v / v)$ FBS (Sigma-Aldrich) was added and cells were centrifuged at $300 \times g$ for $6 \mathrm{~min}$ at $4{ }^{\circ} \mathrm{C}$. In preparation for the FACS staining, cells were washed using $10 \mathrm{~mL}$ of sorting buffer [HBSS with $0.5 \%(\mathrm{w} / \mathrm{v})$ bovine serum albumin (Sigma-Aldrich) and $2 \mathrm{mmol} / \mathrm{L}$ EDTA]. After centrifugating the suspension at $300 \times g$ for $6 \mathrm{~min}$ at $4{ }^{\circ} \mathrm{C}$ and discarding the supernatant, cells were incubated with FC-receptor blocking reagent (BD Bioscience) for $10 \mathrm{~min}$ at $4{ }^{\circ} \mathrm{C}$. Subsequently, antibody mixtures containing anti-CD11b-APC, anti Ly6G-FITC and anti Ly6C-PE (all Biolegend) were added to the samples and let to incubate for $30 \mathrm{~min}$ at $4{ }^{\circ} \mathrm{C}$. Samples were washed twice with sorting buffer, resuspended in sorting buffer, passed through a $70 \mu \mathrm{m}$ cell strainer and DAPI (Sigma-Aldrich) was added to stain dead cells. Sorting was performed using a BD FACSDiva (BD Bioscience) using a $100 \mu \mathrm{m}$ nozzle and gating for $\mathrm{CD} 11 \mathrm{~b}^{+} \mathrm{Ly}_{6} \mathrm{C}^{+} \mathrm{Ly}_{6 \mathrm{G}}$ and $\mathrm{CD}_{11 b^{+}} \mathrm{Ly} 6 \mathrm{C}^{+} \mathrm{Ly}_{6 \mathrm{G}^{+}}$cell populations. Cells were sorted with an efficiency above $86 \%$ and purified cells were kept on ice until further use.

\section{T cell suppression assay}

Splenocytes were isolated from spleens of noninoculated mice by pushing the spleens trough a $70 \mu \mathrm{m}$ cell strainer placed on a $50 \mathrm{~mL}$ tube with the plunger of a $5 \mathrm{~mL}$ syringe. The cell strainer was washed with $5 \mathrm{~mL}$ RPMI containing $3 \%$ FBS, the cell suspension was centrifuged at $300 \times g$ for $6 \mathrm{~min}$ at $4{ }^{\circ} \mathrm{C}$, supernatant was discarded and red blood cells within the cell pellet were lysed using $5 \mathrm{~mL}$ lysis buffer for 4 min at RT. After adding $25 \mathrm{~mL}$ RPMI containing $3 \% \mathrm{FBS}$, cells were spun down at $300 \times g$ for 6 min at $4{ }^{\circ} \mathrm{C}$, washed with $10 \mathrm{~mL}$ RPMI containing $10 \%(\mathrm{v} / \mathrm{v}) \mathrm{FBS}$, centrifuged at $300 \times \mathrm{g}$ for $6 \mathrm{~min}$ at $4{ }^{\circ} \mathrm{C}$ and resuspended in $20 \mathrm{~mL}$ RPMI containing $10 \%$ FBS. The splenocyte suspension was filtered using a cell strainer and stained with the membrane dye PKH26 (1.2 $\mu$ L per $1 \times 10^{7}$ splenocytes; Sigma-Aldrich) following manufacturer's instructions. Suppression of $\mathrm{T}$ cell proliferation was assessed by co-culturing $0.5 \times 10^{5} \mathrm{PKH} 26$-stained splenocytes/96-well plate with previously sorted $\mathrm{CD}_{11 b^{+}} \mathrm{Ly}_{6 \mathrm{C}^{+}} \mathrm{Ly} 6 \mathrm{G}^{-}$or $\mathrm{CD} 11 \mathrm{~b}^{+}$ Ly6 $\mathrm{C}^{+} \mathrm{Ly}_{6 \mathrm{G}^{+}}$bone marrow cells from inoculated or non-inoculated mice in RPMI supplemented with $10 \%$ FBS, $1 \%$ (v/v) penicillin/streptomycin (SigmaAldrich), $1 \mathrm{mmol} / \mathrm{L}$ sodium pyruvate (Sigma-Aldrich) and $50 \mu \mathrm{mol} / \mathrm{L} \beta$-mercaptoethanol (Roth). Splenocytes were stimulated with murine CD3/CD28 Dynabeads (1:1 ratio with splenocytes; Thermo Fisher Scientific) and $30 \mathrm{U} / \mathrm{mL}$ murine rIL-2 (Peprotech). Cells from non-inoculated mice were co-cultured $1: 1$, whereas cells from inoculated mice were co-cultured $1: 1$ and $0.5: 1$ with PKH26-stained splenocytes. The cocultures were incubated for $4 \mathrm{~d}$ at $37^{\circ} \mathrm{C}$ and $5 \% \mathrm{CO}_{2^{\prime}}$ after which $\mathrm{T}$ cell proliferation was assessed by flow cytometry using CD3-FITC, CD4-Alexa Fluor 700 and CD8 $\alpha$-APC antibodies (all Biolegend) and DAPI to visualise dead cells. Proliferation was normalised to T cells stimulated with CD3/CD28 Dynabeads and rIL-2, which were set to $100 \%$. Flow cytometric data was analysed using the Kaluza Analysis software (Beckman Coulter Life Sciences).

\section{CFU quantification}

CFU were quantified for soft tissue, bone, bone marrow supernatant and implant. Soft tissue or femoral bones were placed into $10 \mathrm{~mL}$ PBS and homogenised mechanically using Omni Tissue Homogenizer and Hard Tissue Homogenizing tips, respectively (both Omni International, Kennesaw, GA, USA). Implants were sonicated at $40 \mathrm{kHz}$ for $3 \mathrm{~min}$ in $5 \mathrm{~mL}$ of PBS in an ultrasonic bath (Bandelin Sonorex, Berlin, Germany). Serial dilutions were made from all 4 type of samples per mouse and $10 \mu \mathrm{L}$ of these dilutions were plated in triplicate on $5 \%$ horse blood agar plates (Oxoid). Plates were incubated at $37^{\circ} \mathrm{C}$ and CFUs were determined after 24 and $48 \mathrm{~h}$.

\section{Data analysis}

Data were analysed and visualised with GraphPad Prism 8 (GraphPad Software). Normality of data was checked using a Shapiro-Wilk test and by visually assessing QQ plots from the data. Parametric data was assessed using a Sidak multiple comparison test or a two-way ANOVA, whereas non-parametric data was examined using a Dunn's multiple comparison test. $p<0.05$ was considered statistically significant.

\section{Results}

\section{Clinical evaluation and animal welfare}

Of the 74 operated mice, 60 were included in the final bacteriological and histological evaluation. 14 were operated but sacrificed before study completion and excluded from further analysis. 12 of these excluded 
mice were sacrificed because of a fracture of the proximal femur, 1 animal had an open, draining wound at the surgical site and 1 was excluded for unstable fixation of the plate caused by screw loosening. The lost animals were not replaced. Upon study completion, all groups for histopathology had 6 mice per group, except for the inoculated groups evaluated after 7 and $21 \mathrm{~d}$ (both 5 mice) and $28 \mathrm{~d}$ (4 mice) due to losses described above. The animals operated for CFU quantification and ex vivo cell culture had 5 mice per group after losing 1 mouse per group.

Non-inoculated mice gained on average $2.5 \%$ body weight after $28 \mathrm{~d}$, while inoculated mice lost on average $6.5 \%$ body weight (data not shown).

\section{Radiographic and histopathological evaluation}

The double femoral osteotomy model generated a $2 \mathrm{~mm}$ bone segment. At $3 \mathrm{~d}$, non-inoculated mice did not show any signs of bone healing between the bone segment and the adjacent femoral bone (Fig. 1a-b). By $14 \mathrm{~d}$, some early signs of healing were observed (Fig. 1c) with newly formed woven bone or soft

\section{Non-inoculated}
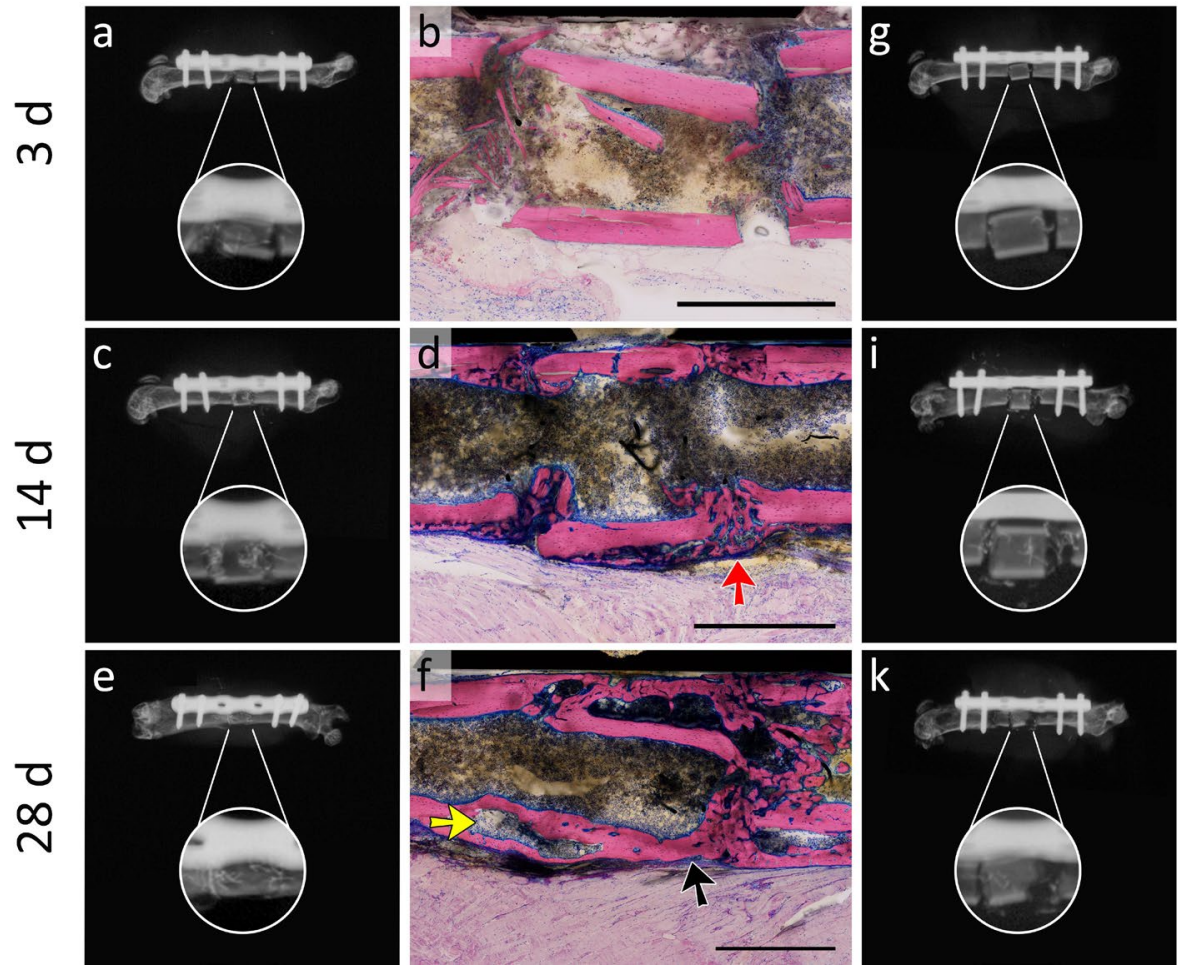

Inoculated

Fig. 1. Radiographic and histological appearance of non-inoculated and inoculated mice at 3, 14 and 28 d post-surgery. Representative radiographs and G\&E-stained MMA-embedded sections of (a-f) noninoculated or (g-l) S. aureus-inoculated mouse femoral bone at day 3 (upper row), 14 (middle row) and 28 (lower row) post-surgery. Mice received a double osteotomy within the femur, which created a bone segment, and a titanium 6-hole MouseFix locking plate for bone stabilisation. Non-inoculated animals showed signs of fracture consolidation, whereas inoculated mice still had a non-union $28 \mathrm{~d}$ post-surgery. G\&E stained bone in pink and connective and soft tissue in purple, whereas nuclei are dark blue. Red arrows indicate bone regeneration, black arrows show bone resorption pits created by osteoclasts, white arrowheads point out bacterial aggregates and the yellow arrow indicate bone marrow within newly formed bone. Note, the samples of the non-inoculated mice stained more in brown within the bone marrow. This is an artifact due to incomplete dehydration and defatting. Black debris were remains of the Gigly wire used to make the double osteotomy. Scale bars: $1 \mathrm{~mm}$. 
mice, no fracture consolidation was visible in the inoculated animals after $28 \mathrm{~d}$ and their osteotomy ends were irregularly shaped, suggestive of osteolysis (Fig. 1k). Bacterial aggregates and remnants of osteoclast activity were detected (Fig. 11; arrowhead and black arrow, respectively). Newly formed bone that was loosely arranged could also be observed in inoculated mice $28 \mathrm{~d}$ post-surgery (Fig. 11; red arrow) but this was minor compared to non-inoculated mice and severe bone osteolysis prevailed.

Additionally, samples of non-inoculated and inoculated mice were evaluated by scoring for boneinfection-related features using HOES (Tiemann et al., 2014) (Fig. 2a) and immunostainings were performed to detect the presence of neutrophils, fibrin(ogen) and macrophages in the distal part of the bone segment

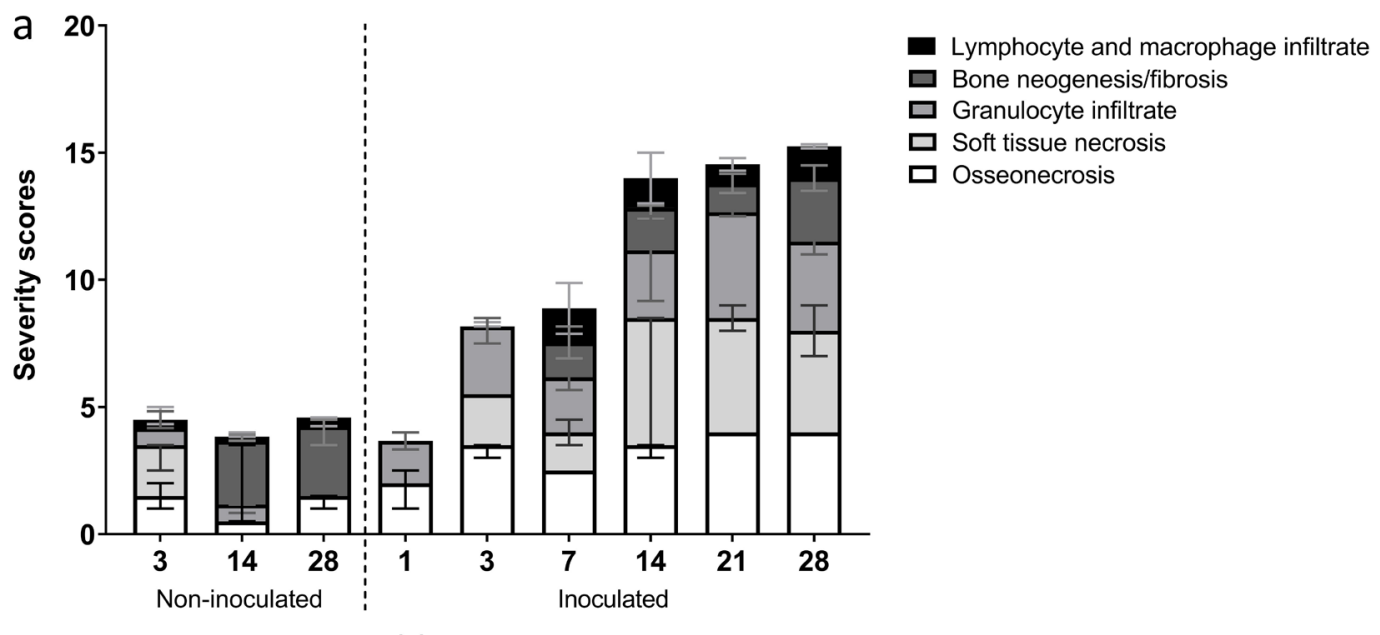

Day(s) post-operative
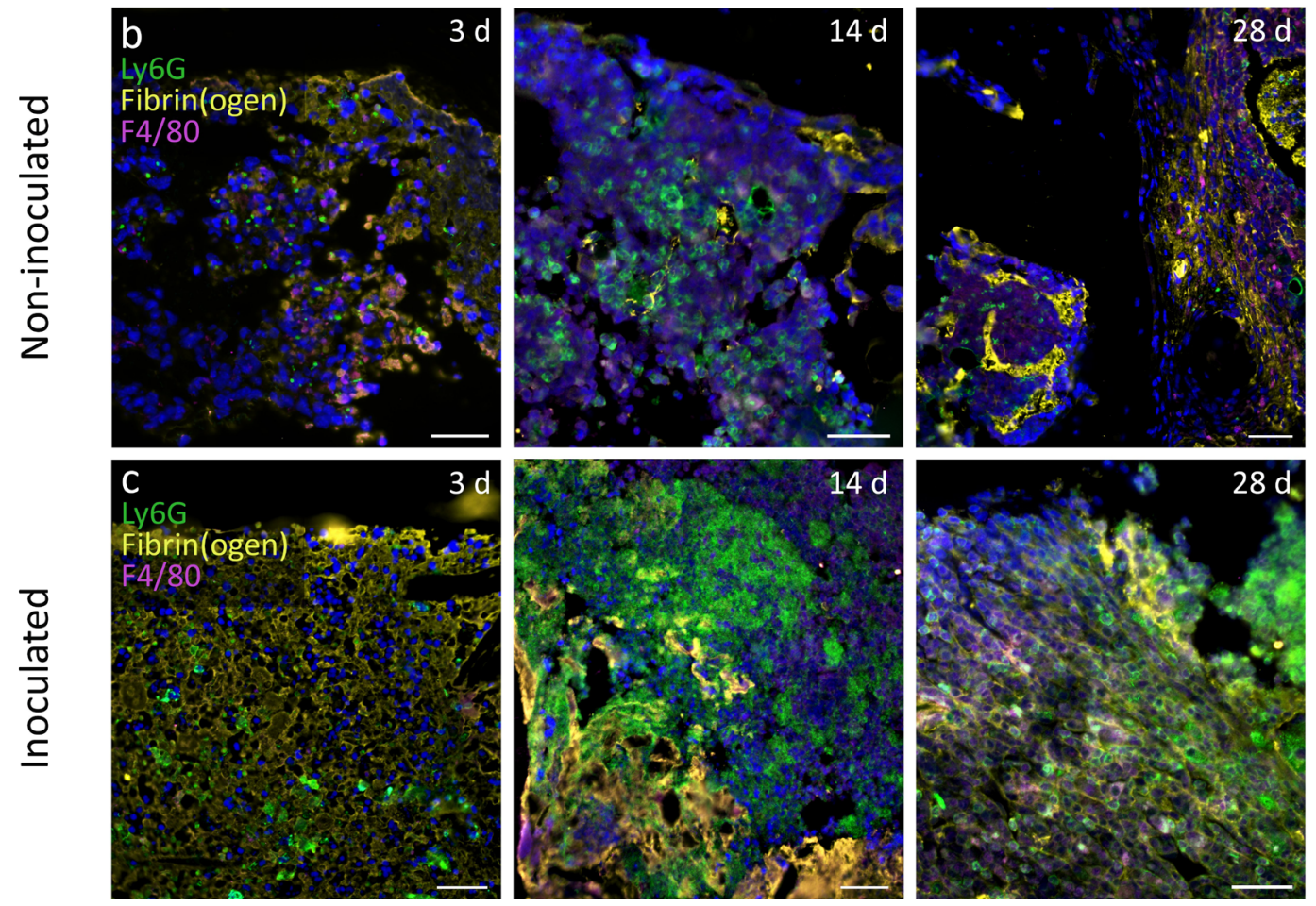

Fig. 2. Histopathological evaluation of non-inoculated and S. aureus-inoculated mice. (a) HOES of noninoculated mice at 3, 14 and $28 \mathrm{~d}$ post-surgery and mice with a $S$. aureus-inoculated femoral bone segment assessed at 1, 3, 7, 14, 21 and $28 \mathrm{~d}$ post-infection. From bottom to top, the acute osteomyelitis features investigated were granulocyte infiltration (white), osseonecrosis (light grey) and soft tissue necrosis (medium grey); the chronic osteomyelitis features assessed were bone neogenesis/fibrosis (dark grey) and lymphocyte and macrophage infiltrate (black). Data shown are medians of HOES scores with $95 \%$ confidence intervals from $n=2$ for inoculated mice at 7 and $28 \mathrm{~d}$ post-surgery and $n=3$ for the rest of the data. Representative images of host responses in paraffin-wax-embedded murine femoral bone of (b) non-inoculated and (c) $S$. aureus-inoculated mice at 3, 14 and $28 \mathrm{~d}$ post-surgery. For consistency, images were taken from the distal part of the bone segment of non-inoculated mice and inoculated mice. Immunofluorescent triple stains were performed for Ly6G (neutrophils, green), fibrin(ogen) (yellow) and F4/80 (macrophages, violet). DAPI (dark blue) was used as a nuclear counterstain. Scale bar: $50 \mu \mathrm{m}$. 

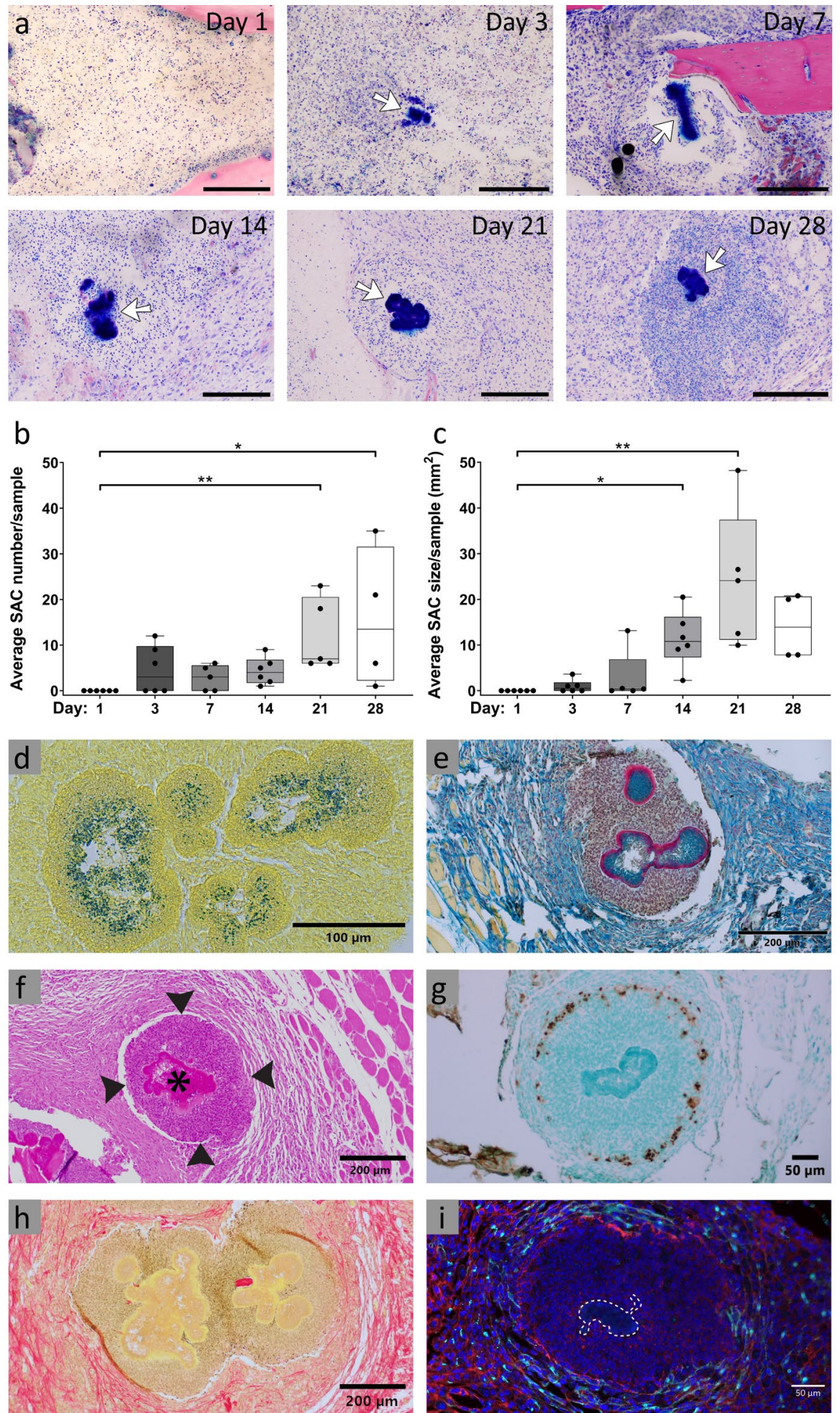

Fig. 3. Assessment of SACs and abscesses in femoral bone marrow of $S$. aureus-inoculated mice. (a) G\&E-stained MMA-embedded femoral bone marrow of $S$. aureus-inoculated mice from 1, 3, 7, 14, 21 and $28 \mathrm{~d}$ post-surgery. Images are representative and focused on abscess structures with SACs, indicated with white arrows, present in the bone marrow. Scale bar: $200 \mu \mathrm{m}$. SAC (b) number and (c) size measured in paraffin-wax- and MMA-embedded femoral bone marrow of $S$. aureus-inoculated mice 1, 3, 7, 14, 21 and $28 \mathrm{~d}$ post-surgery. Statistical test used: Dunn's multiple comparison test. Data are medians \pm max and min values of average SAC number and size per animal. $n=6$ for 1,3 and $14 \mathrm{~d}, n=5$ for 7 and $21 \mathrm{~d}$ and $n=4$ for $28 \mathrm{~d}$ post-surgery. ${ }^{*} p<0.05,{ }^{*} p<0.01$. Representative images of SACs in paraffin-wax-embedded murine femoral bone inoculated with $S$. aureus from 21 or $28 \mathrm{~d}$ stained with (d) BB for Gram ${ }^{+}$bacteria (blue); (e) picroMallory trichrome for fibrin (magenta); (f) H\&E, with a SAC indicated by an asterisk and host cells within an abscess by arrowheads; (g) TUNEL assay for apoptotic host cells, with methyl green as a counterstain (brown); (h) picro-Sirius for collagen fibres (red); (i) immunofluorescent antibodies for fibrin(ogen), $\alpha \mathrm{SMA}$ for myofibroblasts, with DAPI as a nuclear counterstain and the SAC indicated by a dashed white line (red, turquoise and dark blue, respectively). 
(Fig. 2b,c). Non-inoculated mice had a low degree of osseonecrosis at 3, 14 and $28 \mathrm{~d}$. Soft tissue necrosis was only observed at $3 \mathrm{~d}$, whereas granulocytes were present in bone and surrounding tissue at 3 and $14 \mathrm{~d}$. A fibrin clot within the osteotomy gap was observed at $3 \mathrm{~d}$, which evolved in fibrous tissue. Both the presence of fibrous tissue and bone neogenesis was noted from $14 \mathrm{~d}$ on, while lymphocytes and macrophages were present at all time points. Noninoculated mice did not have acute osteomyelitis according to the HOES scoring system (i.e. the sum of osseonecrosis, soft tissue necrosis and granulocyte infiltrate scores was lower than 6).

In inoculated mice, from 1 to $28 \mathrm{~d}$, osseonecrosis was observed in the bone segment and adjacent the femoral bone. The soft tissue above the implant became necrotic at $3 \mathrm{~d}$ and this increased at later time points. Large numbers of granulocytic cells were located within muscle and bone tissue at all time points together with many fibrin(ogen) fibres. Regeneration started from $7 \mathrm{~d}$ and continued until $28 \mathrm{~d}$, indicated by bone neogenesis and fibrous tissue formation. Aside from granulocytes, from $7 \mathrm{~d}$ on, lymphocytes and macrophages also began infiltrating into bone and soft tissue from $7 \mathrm{~d}$ onwards. From $14 \mathrm{~d}$, animals no longer had an acute infection but had transitioned to what is considered a chronically florid/active infection according to the HOES score (sum of all features was higher than 9). At later time points, mice had still not transitioned to a chronic infection since the sum score of bone neogenesis/ fibrosis and lymphocyte and macrophage infiltration was lower than 6, granulocytes were still present even after $28 \mathrm{~d}$ of infection and only minor signs of bone regeneration were observed.

\section{SACs}

In inoculated animals, abscess structures were observed within bone marrow from $3 \mathrm{~d}$ onwards (Fig. 3a). In addition to the numerous abscesses observed, some biofilms on screws and implant were also present (data not shown). At the centre of the abscess, SACs were observed that appeared as dense blue-staining structures in G\&E-stained sections (Fig. 3a, white arrows). From $14 \mathrm{~d}$ onwards, all inoculated animals had SACs, with significantly more SACs at 21 and $28 \mathrm{~d}$ compared to $1 \mathrm{~d}$ (Fig. 3b). SAC size significantly increased from $1 \mathrm{~d}$ to 14 and $21 \mathrm{~d}$ (Fig. 3c). Examination of a SAC and abscess in more detail showed that the centre of a SAC contained Gram bacteria (Fig. 3d; blue). These bacteria were covered with a pseudocapsule consisting of fibrin fibres (Fig. 3e; magenta). Around the SAC (Fig. 3f, asterisk) many leukocytes were present (Fig. 3f, arrowheads), which, together with the SAC, were mostly alive (Fig. 3g; green). Also, a rim of apoptotic cells was observed that did not border the SAC (Fig. 3g; brown). The SAC and its surrounding cells were encapsulated by layers of oriented but not consolidated collagen fibres (Fig. 3h; red) and fibrin(ogen) strands (Fig. 3i; red) and by $\alpha \mathrm{SMA}^{+}$myofibroblasts (Fig. 3i; turquoise). Together, the SAC, adjacent immune cells and encapsulation formed the complete structure of what is named as abscess in the text below.

\section{Immune cell infiltration towards SACs}

To investigate which immune cells were associated with $S$. aureus aggregates/SACs present during acute or chronically florid infection, immunostainings with markers for different immune cells were performed at 7 and $21 \mathrm{~d}$, respectively. Bone marrow after $7 \mathrm{~d}$ of infection (overview in Fig. 4a) contained a small number of $S$. aureus aggregates with few bacteria per aggregate together with some $\mathrm{Ly}_{6} \mathrm{G}^{+}$neutrophils and F4/80 ${ }^{+}$macrophages (Fig. 4 b). Successive sections showed that some Ly6C $\mathrm{C}^{+}$monocytes and $\mathrm{CD}_{11 b^{+}}$ myeloid cells were also dispersed around the same area of the S. aureus aggregates (Fig. 4c). At this time, no iNOS, Arg-1-expressing cells (Fig. 4d) or FOXP3 ${ }^{+}$ Tregs were observed (Fig. 4e) neither organised structures were seen.

By $21 \mathrm{~d}$, clearly defined abscess structures were observed in the bone marrow (Fig. 4f), with a central SAC staining positive for S. aureus (Fig. $4 \mathrm{~g}$; edge of the SAC is depicted). The SAC was surrounded by highly $\mathrm{Ly} 6 \mathrm{G}^{+}$neutrophils and a small number of $\mathrm{F} 4 / 80^{+}$macrophages at the border (Fig. $4 \mathrm{~g}$; white arrowheads). Some cells within the abscess were positive for the monocyte marker Ly6C and the leukocyte marker CD11b (Fig. 4h). iNOS ${ }^{+}$and Arg $-1^{+}$cells at the border of the abscess formed into somewhat organised arrangements within the abscess (Fig. 4i; white arrows). FOXP3 ${ }^{+}$Tregs cells were present outside the abscess (Fig. 4j).

To further probe the cell populations within the abscess after $21 \mathrm{~d}$ of infection, and particularly to investigate neutrophil, monocyte and macrophage cell surface markers as well as the enzymes iNOS and Arg-1 used by macrophages but also MDSCs, further high magnification images were taken (Fig. 5). Fig. 5a-b shows the Ly6G neutrophil marker in combination with iNOS and Arg-1. The neutrophils (Ly6G) in close proximity to the SAC at the centre of the abscess expressed Arg-1 but not iNOS (Fig. 5a and b). H\&E staining of the same section confirmed these locations contained neutrophils with either banded or partially segmented nuclei (Fig. 5c; white arrows). These neutrophils appeared intact and alive.

Co-localisation of iNOS and Arg-1 with Ly6C, a monocyte marker, is shown in Fig. 5d,e. Highly Ly6C ${ }^{+}$cells were observed at the border of the abscess where the staining co-localised with both iNOS and Arg-1 staining (Fig. 5d,e). Such iNOS ${ }^{+}$and Arg- $1^{+}$ monocytic cells were not present at the centre of the abscess, near the SAC. H\&E staining showed cells with morphological characteristics of monocytes, in the same areas at the edge of the abscess where the Ly6C ${ }^{+}$, iNOS $^{+}$and Arg- $1^{+}$cells were located (Fig. 5f; black arrows).

Co-localisation of iNOS and Arg-1 with F4/80, a macrophage marker, is shown in Fig. 5 g,h. Few F4/80+ macrophages were observed, but those present were 
generally seen at the periphery of the abscess and were strongly Arg- $1^{+}$and expressed iNOS to a lesser extent (Fig. 5g,h), indicative of an anti-inflammatory, M2 phenotype. The H\&E staining also confirmed the presence of macrophages at this location (Fig. 5i; white arrowhead). F4/80- and Arg-1-expressing M2 macrophages were observed outside of the abscess as well.

$\mathrm{T}$ cell suppression by $\mathrm{CD} 11 \mathrm{~b}^{+} \mathrm{Ly} \mathrm{C}^{+} \mathrm{Ly} 6 \mathrm{G}^{-}$or $\mathrm{CD}_{11 b^{+} \mathrm{Ly}^{6} \mathrm{C}^{+} \mathrm{Ly} 6 \mathrm{G}^{+} \text {bone marrow cells }}$

To assess whether monocytes and/or neutrophils from non-inoculated or inoculated mice had immune suppressive capabilities, CD11b ${ }^{+} \mathrm{Ly}_{6 \mathrm{C}^{+}} \mathrm{Ly}_{6 \mathrm{G}}^{-}$ monocytes or $\mathrm{CD}_{11 b^{+}} \mathrm{Ly}_{6 \mathrm{C}^{+}} \mathrm{Ly}_{6 \mathrm{G}^{+}}$neutrophils were purified from non-inoculated bone marrow or

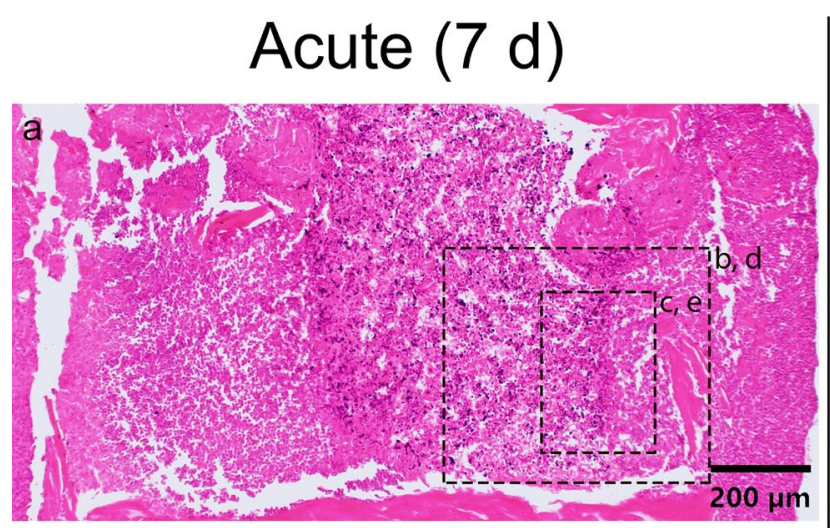

bone marrow with many abscesses and SACs. CFU quantifications showed that non-inoculated mice did not have any detectable viable bacteria within soft tissue, bone and bone marrow samples or on implants after $21 \mathrm{~d}$ (Fig. 6a). In contrast, the samples from inoculated mice contained larger numbers of bacteria varying from 5 to $6.5 \log _{10}$ total CFU, demonstrating that the inoculated animals were indeed infected after $21 \mathrm{~d}$.

There was a significant difference in the percentage of monocytic CD $11 b^{+} \mathrm{Ly}_{6 \mathrm{C}^{+}} \mathrm{Ly} 6 \mathrm{G}^{-}$cells and neutrophilic CD $11 b^{+}$Ly $6 \mathrm{C}^{+} \mathrm{Ly}_{6 \mathrm{G}^{+}}$cells from the total bone marrow cell population between inoculated mice and non-inoculated mice (Fig. 6b).

A $\mathrm{T}$ cell suppression assay was performed with the purified monocytic CD11b+ $\mathrm{Ly} 6 \mathrm{C}^{+} \mathrm{Ly}^{-} \mathrm{G}^{-}$cells
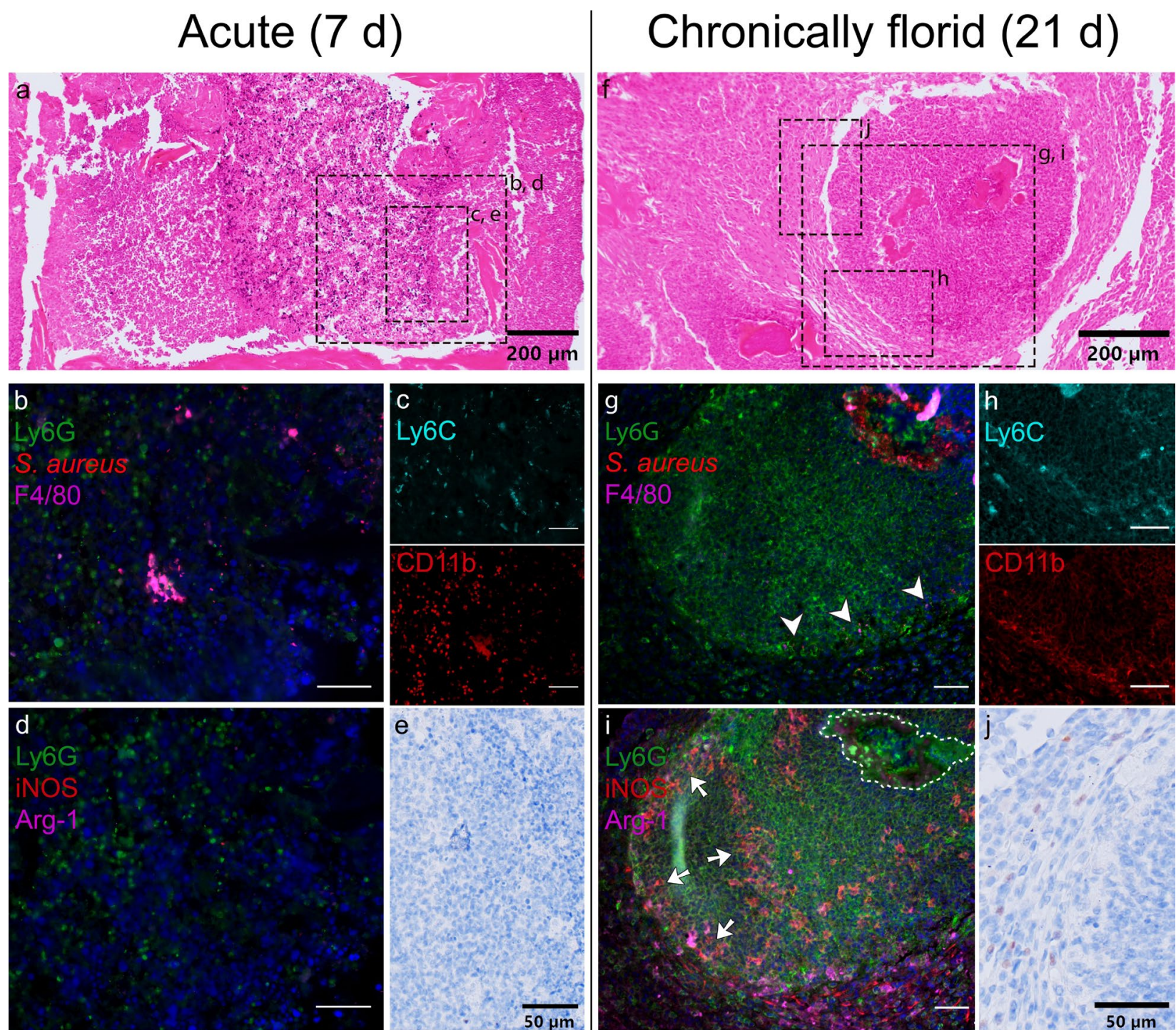

Fig. 4. Host cells associated with $S$. aureus aggregates in paraffin wax sections of inoculated mice 7 and 21 d post-surgery. (a) H\&E, (b-d) immunofluorescent and (e) immunostaining of bone marrow within the S. aureus-infected segment after $7 \mathrm{~d}$. (f) H\&E, (g-i) immunofluorescent and (j) immunostaining of bone marrow with an abscess containing SACs after $21 \mathrm{~d}$. Successive sections were used for S. aureus (red), Ly6G (neutrophils, green), F4/80 (macrophages, violet, white arrowheads), Ly6C (monocytic cells, turquoise), CD11b (pan-myeloid cells, red), iNOS (enzyme NO production, red), Arg-1 (enzyme urea cycle, violet), DAPI (nuclei, dark blue) and FOXP3 (brown) to visualise Tregs. Rim of cells positive for iNOS and Arg-1 are indicated by white arrows and co-localisation of Ly6G, F4/80 and S. aureus signals shown as a light pink colour. Scale bar: (b-d and g-i) $50 \mu \mathrm{m}$. 


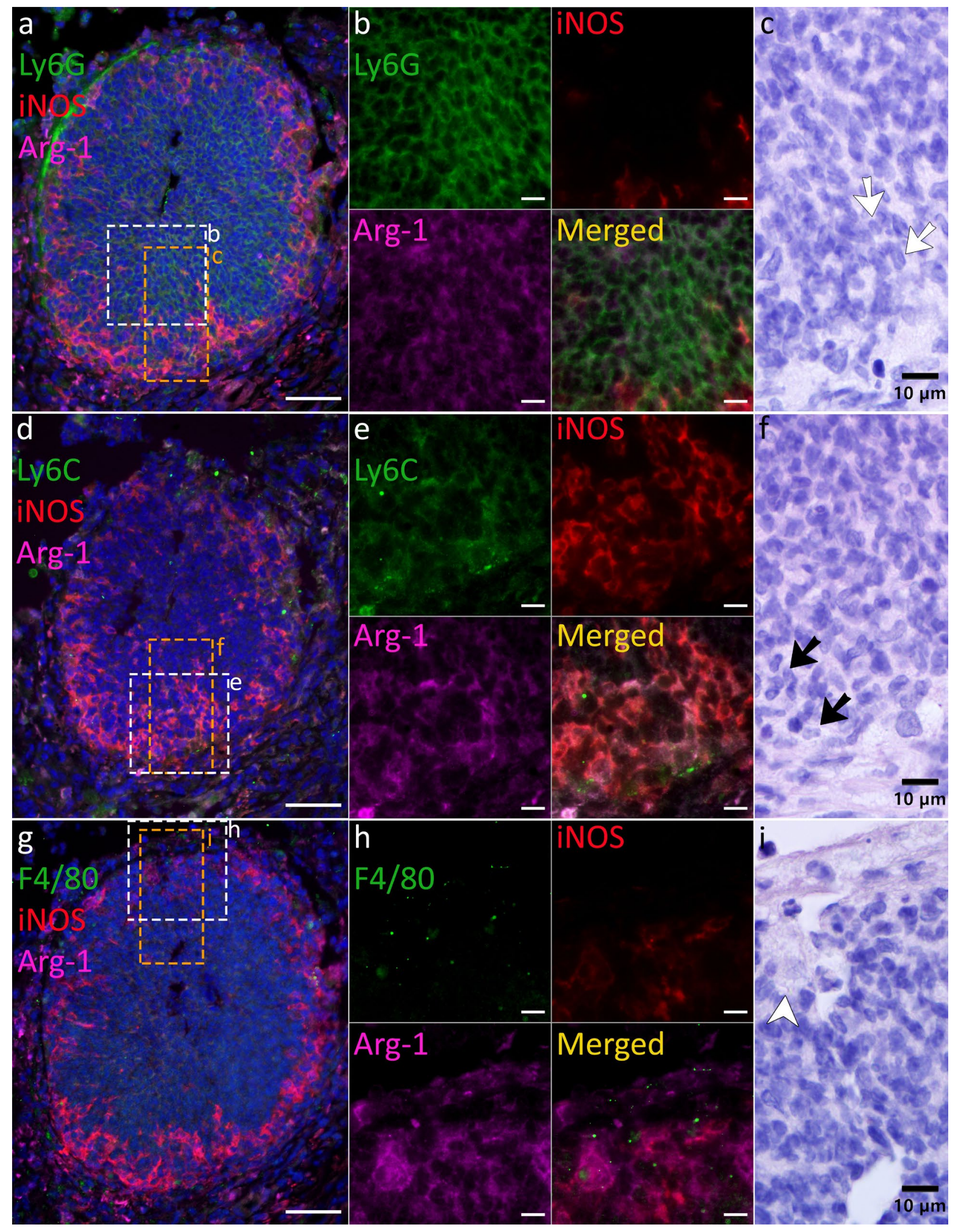

Fig. 5. Innate immune cells within a bone marrow abscess of an S. aureus-inoculated murine FRI model $21 \mathrm{~d}$ post-surgery. Immunofluorescent staining for $(\mathbf{a}, \mathbf{b})$ either Ly6G (neutrophils, green), (d,e) Ly6C (monocytic cells, green) or (h,g) F4/80 (macrophages, green) co-stained with iNOS (enzyme NO production, red) and Arg-1 (enzyme urea cycle, violet) and subsequently stained with (c,f,i) H\&E. DAPI (nuclei, dark blue) was used as a counter stain for the fluorescent lower magnification images. In the H\&E images, white arrows indicate neutrophils, black arrows show monocytes and a white arrowhead points out a macrophage. Scale bars: (a,d,g) $50 \mu \mathrm{m}$ and (b,e,h) $10 \mu \mathrm{m}$. 
or neutrophilic CD $11 b^{+} \mathrm{Ly}_{6 \mathrm{C}^{+}} \mathrm{Ly}_{6 \mathrm{G}^{+}}$cells to detect possible suppressive capabilities. When examining the effects on the total $\mathrm{CD}^{+} \mathrm{CD}^{+} \mathrm{T}$ cell fraction, it was observed that monocytic D11b ${ }^{+} \mathrm{Ly}_{6 \mathrm{C}^{+}} \mathrm{Ly}_{6 \mathrm{G}}$ cells from inoculated mice strongly suppressed $\mathrm{T}$ cell proliferation in a ratio-dependent manner, whereas the same cell type from non-inoculated mice did not suppress $\mathrm{T}$ cell proliferation (Fig. 6c). Neutrophilic $\mathrm{CD}_{11 b^{+}} \mathrm{Ly}_{6 \mathrm{C}^{+}} \mathrm{Ly}_{6 \mathrm{G}}{ }^{+}$cells from non-inoculated mice also did not have suppressive activity towards $\mathrm{CD}^{+} \mathrm{CD}^{+} \mathrm{T}$ cells. However, neutrophilic CD11b ${ }^{+}$ $\mathrm{Ly}_{6 \mathrm{C}^{+}} \mathrm{Ly}_{6 \mathrm{G}} \mathrm{G}^{+}$cells from inoculated mice significantly suppressed $\mathrm{CD}^{+} \mathrm{CD}^{+} \mathrm{T}$ cell proliferation (Fig. 6c). Similar results were observed for $\mathrm{CD}^{+} \mathrm{CD} 8 \alpha^{+} \mathrm{T}$ cell co-cultured with monocyte or neutrophil fractions from non-inoculated or inoculated mice, although neutrophilic cells from inoculated mice suppressed $\mathrm{CD}^{+} \mathrm{CD} 8 \alpha^{+} \mathrm{T}$ cells less than monocytic cells (Fig. $6 \mathrm{~d}$ ).

\section{Discussion}

To get a better understanding of the pathophysiology of an FRI, the histopathological changes that occur in an FRI mouse model were examined over time and compared to normal fracture healing processes in non-inoculated mice. The infection in this model progressed into an active, a so-called, chronically florid infection, with constant granulocytes presence, severe osteolysis of the operated femur and many abscesses containing SACs within the bone marrow of the osteotomy segment and adjacent a

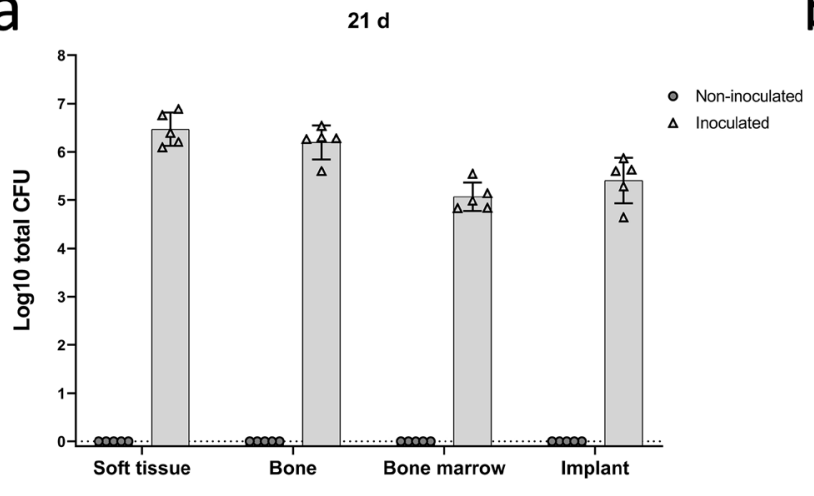

b

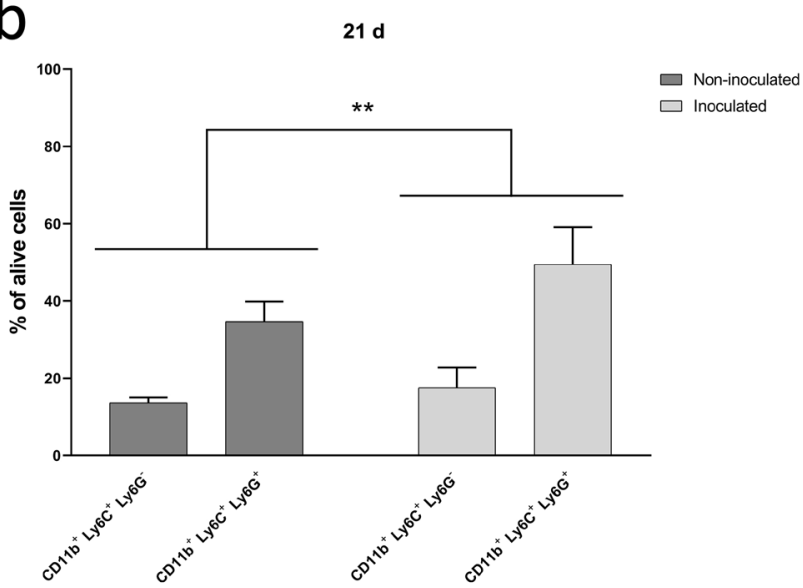

C

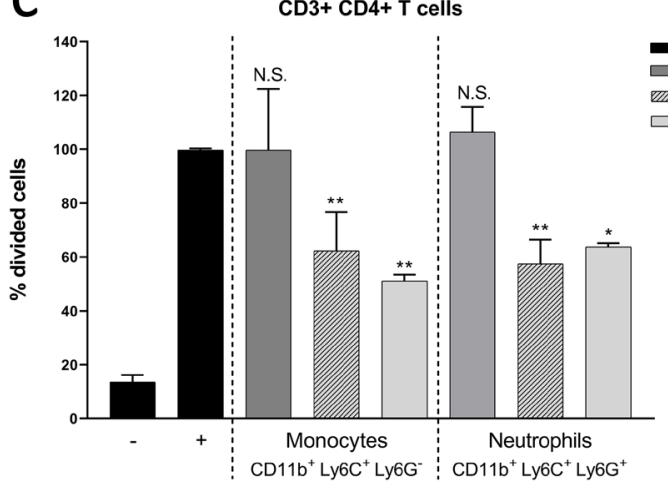

d
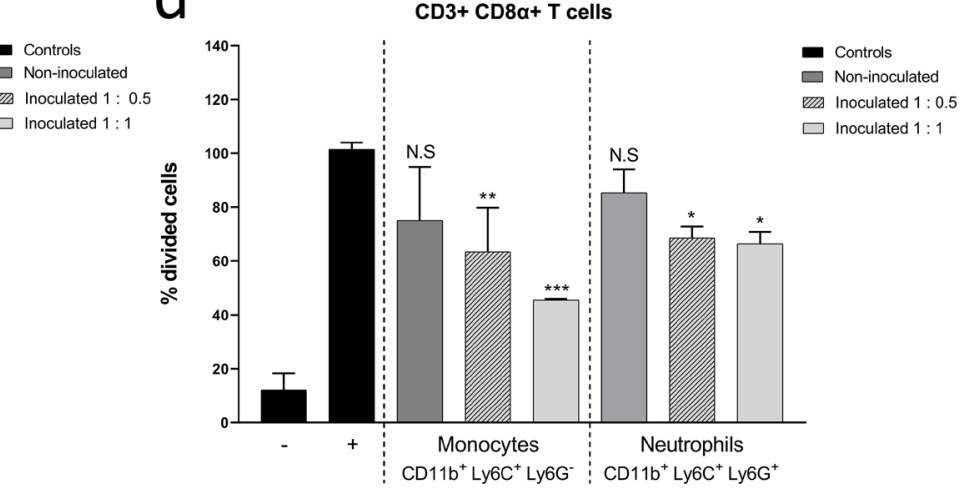

Fig. 6. Evaluation of CFU and monocyte and neutrophil populations in non-inoculated and S. aureusinoculated mice $21 \mathrm{~d}$ post-operative. (a) CFU quantification of soft tissues, bones, bone marrow supernatants and implants from non-inoculated (circles) or S. aureus-inoculated (triangles) mice used for purification of $\mathrm{CD}_{11 \mathrm{~b}^{+}} \mathrm{Ly}_{6 \mathrm{C}^{+}} \mathrm{Ly}_{6 \mathrm{G}^{-}}$monocytic or $\mathrm{CD} 11 \mathrm{~b}^{+} \mathrm{Ly}_{6 \mathrm{C}^{+}} \mathrm{Ly}_{6 \mathrm{G}}{ }^{+}$neutrophilic bone marrow cells $21 \mathrm{~d}$ post-surgery. Data are means \pm SD $(n=5)$. (b) Percentage of monocytic CD11b ${ }^{+}$Ly $^{6} \mathrm{C}^{+} \mathrm{Ly}_{6 \mathrm{G}}{ }^{-}$or neutrophilic CD11 $\mathrm{b}^{+}$ Ly $6 \mathrm{C}^{+} \mathrm{Ly} 6 \mathrm{G}^{+}$cells from all alive bone marrow cells of non-inoculated (dark grey) or S. aureus-inoculated mice (light grey). Statistical test used: two-way ANOVA comparing cell percentages of inoculated and noninoculated mice. Data presented are means $\pm \mathrm{SD}(n=5)$. Percentage proliferating $(\mathbf{c}) \mathrm{CD}^{+} \mathrm{CD}^{+} \mathrm{T}$ cells or $(\mathbf{d})$ $\mathrm{CD}^{+} \mathrm{CD} 8 \alpha^{+} \mathrm{T}$ cells cultured alone without or with $\mathrm{CD} 3 / \mathrm{CD} 28$ Dynabeads and rIL2 stimulation (black - or + , respectively) or co-cultures with monocytic CD11b+ $\mathrm{Ly}_{6 \mathrm{C}^{+}} \mathrm{Ly}_{6 \mathrm{G}^{-}}$or neutrophilic CD11b $\mathrm{b}^{+} \mathrm{Ly} 6 \mathrm{C}^{+} \mathrm{Ly}_{6 \mathrm{G}} \mathrm{G}^{+}$ bone marrow cells from non-inoculated ( $1: 1$ ratio, dark grey) or $S$. aureus-inoculated mice $(1: 1$ ratio, light grey; $0.5: 1$ ratio, striped light grey). Statistical test used: Sidak multiple comparison test. Data are means $\pm \mathrm{SD}(n=5)$, stimulated T cells cultured alone were set as $100 \%$ and used as comparison for the statistical tests. N.S.: non-significant, ${ }^{*} p<0.05,{ }^{* *} p<0.01,{ }^{* * *} p<0.001$. 
femoral bone. The SACs were covered by a fibrin pseudocapsule surrounded by neutrophils and by an early encapsulation comprised of fibrinogen and collagen. Furthermore, the $S$. aureus infection led to functionally suppressive monocytes and neutrophils and immunohistochemistry revealed the presence of many neutrophils and a few monocytes, antiinflammatory macrophages (M2) and Tregs.

The most obvious feature of the $S$. aureus infection in the histological sections were the $S$. aureus aggregates, or immature SACs, which were present in the bone marrow of inoculated mice after $3 \mathrm{~d}$. By inoculating the bacteria directly into the bone marrow of the double osteotomy-induced bone segment, a deep osteomyelitis with high chances of SAC formation was preferentially seeded, with relatively less chance for an implant-related biofilm infection. The SACs and abscesses surrounding them evolved into more distinct structures over time. Once matured, the abscesses appeared to be encapsulated by myofibroblasts with collagen and fibrin(ogen) fibres, possibly as an attempt by the host to contain the infection (Kobayashi et al., 2015) and shield it off from neighbouring, healthy tissue. The SACs themselves were surrounded by a fibrin pseudocapsule, which is formed by the action of $S$. aureus within the SAC. $S$. aureus is known to bind fibrin(ogen) using proteins such as ClfA, Emp and Eap (Chavakis et al., 2005; Foster et al., 2014). Furthermore, it has the ability to activate host prothrombin with Coa and vWbp to convert fibrinogen into fibrin (Bjerketorp et al., 2004; Friedrich et al., 2003; Thomer et al., 2016b). Others have suggested that the pseudocapsule around SACs contains fibrin (Cheng et al., 2011; Thomer et al., 2016b), which was confirmed in the present study using a histochemical staining for fibrin. Immunostainings with an anti-fibrin(ogen) antibody did not stain the pseudocapsule directly around SACs in the present and previous studies (Cheng et al., 2010; Farnsworth et al., 2017). However, the fibrin pseudocapsule did stain positive for fibrin when using the histochemical picro-Mallory trichrome staining (Fig. 3e). The picroMallory staining does not depend on antigen binding sites but rather, by combining three different dyes and two staining differentiators, the acid fuchsin stain is retained specifically in the fibrin (Lendrum et al., 1962). The fibrin pseudocapsule of an in vitro SAC also is stained in magenta, indicative of fibrin, when the picro-Mallory staining is applied (Hofstee et al., 2020b). Furthermore, in vitro, the fibrin pseudocapsule around SACs is stained with an anti-fibrin(ogen) antibody (Hofstee et al., 2020b). These observations strongly suggest that the SAC is surrounded by a fibrin pseudocapsule; however, the precise reason for a lack of specific staining in vivo remains unresolved at the present time. Based on the marked accumulation of leukocytes at the edge of the pseudocapsule, it appears that the fibrin pseudocapsule serves to prevent infiltration of immune cells into the SAC and that its formation is one of the key $S$. aureus mechanisms to escape from host responses, as previously suggested (Cheng et al., 2011; Masters et al., 2019; Thomer et al., 2016b). Recently Hofstee et al. (2020b) have shown, using an in vitro SAC model, that indeed fibrin is abundantly present in the SAC pseudocapsule and this prevents neutrophils from invading a SAC. Moreover, a fibrin pseudocapsule also inhibits the diffusion of antibiotics into the SAC (Hofstee et al., 2020b).

$S$. aureus aggregation with fibrin or SAC formation may be a target for future FRI therapy and has indeed been shown to be an effective target in, for example, S. aureus-related renal infections and endocarditis. Vaccines against Emp and Eap lower abscess numbers
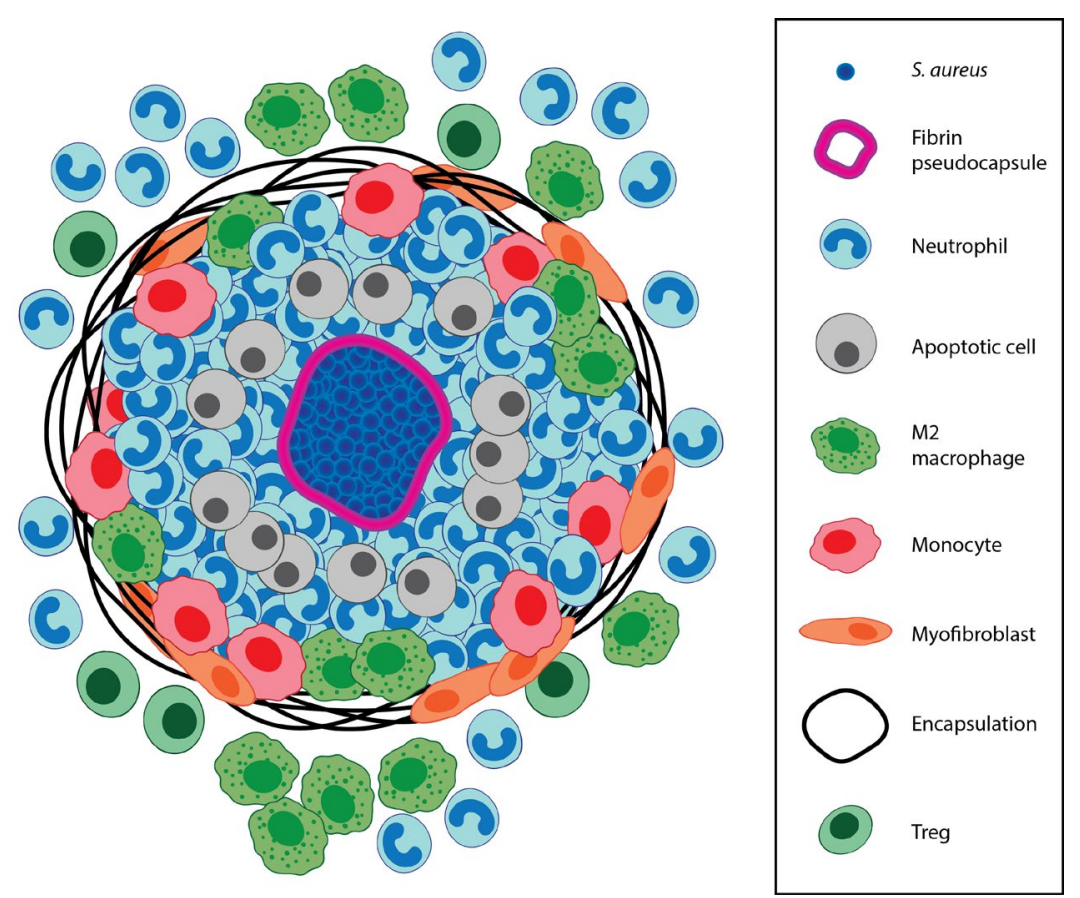

Fig. 7. Schematic overview of the different components of an abscess as observed in a murine FRI model that was partially generated with BioRender (Toronto, ON, Canada). 
in a mouse model of renal S. aureus infection (Cheng et al., 2009). The anticoagulant dabigatran, which prevents the conversion of fibrinogen into fibrin, decreases the severity of $S$. aureus skin infections and lowers subcutaneous abscess volume (Vanassche et al., 2011). A similar approach may be applied for an FRI but given that fibrin is also important for fracture healing, targeting only bacterial proteins involved in the conversion of fibrinogen into fibrin would be preferred. Such a bacterial protein could be Coa, which when bound to prothrombin forms the enzymatically active staphylothrombin. In a murine $S$. aureus bloodstream infection model, mice are less strongly affected when binding of fibrinogen to Coa was prevented with an antibody against the R-domain of Coa (Thomer et al., 2016a). Other possible options would be to target a conserved domain of $\mathrm{vWbp}$, which when bound to prothrombin can also convert fibrinogen into fibrin, or to target ClfA. ClfA can bind fibrinogen/fibrin and has been associated with $S$. aureus aggregation and mice are less affected by $S$. aureus sepsis when treated with an anti-ClfA antibody (McAdow et al., 2011).

Although others have described most of the neutrophils within an $S$. aureus-related abscess to be dead (Cheng et al., 2011; Thomer et al., 2016b) and, normally, neutrophils are considered to be shortlived (Nicolás-Ávila et al., 2017), it is reasonable to assume that the neutrophils surrounding the SAC in the present mouse model were alive, since they did not stain positive with the TUNEL assay and showed morphological features of live cells. Recent literature supports the observation of neutrophils potentially being long lived under certain conditions, such as certain inflammatory conditions. Moreover, they are now believed to be more diverse in their capabilities, e.g. hyper proinflammatory or immunosuppressive, than previously thought (Nicolás-Ávila et al., 2017). Furthermore, microbiota-derived endotoxins and other molecules such as peptidoglycans can influence neutrophil ageing and can prime neutrophil functions to be effective against the infection (Nicolás-Ávila et al., 2017). The bacteria within a SAC might secrete similar factors, which prolong the lifespan of the neutrophils close to the SAC and modulate them to have specific immunomodulatory capabilities; however, this still remains unknown. The TUNEL assay identifies apoptotic cells and possibly also necroptotic cells; in the present study it resulted in a few positive stained cells within the abscess but not bordering the SAC. It would be interesting to examine whether other types of cell death e.g. pyroptosis, autophagy or NETosis (Dąbrowska et al., 2019) occur within an abscess to further elucidate the vitality and death of neutrophils associated with abscesses.

14 mice were excluded from further analysis, 12 of which due to a fracture. The mouse model described in the present study is complex and correct placement of the plate and screws is crucial. Consequently, when done inappropriately, there may be mechanical failures in the early post-operative period, unrelated to infection. At later time points when the infection progressed, there is a risk of screw and implant instability and, thus, fractures due to infectioninduced osteolysis.

$\mathrm{CD}^{+11 b^{+} \mathrm{Ly}^{+} \mathrm{C}^{+} \mathrm{Ly}^{-} \text {monocytes and CD11b }}{ }^{+}$ Ly6C $\mathrm{C}^{+} \mathrm{Ly}_{6 \mathrm{G}^{+}}$neutrophils isolated from bone marrow of inoculated mice functionally suppressed $\mathrm{T}$ cell proliferation. The suppressive action of these monocytes and neutrophils, together with typical MDSC surface markers, identifies these cells to be monocytic and neutrophilic/granulocytic MDSCs, respectively (Bronte, 2016). MDSCs suppress other immune cells and have previously been associated with chronic $S$. aureus infection. Mice intravenously infected with $S$. aureus have MDSCs in their spleen (Tebartz et al., 2015) and in mice with orthopaedic biofilm infection MDSCs are found in tissue surrounding the implant (Heim et al., 2014). Furthermore, human biopsies from PJI patients collected during joint revision surgeries contain MDSC-like cells (Heim et al., 2015b). The presence of these cells is in line with the development of a persistent infection, since suppressive immune responses will interfere with infection clearance (Heim et al., 2015a).

MDSCs suppress other immune cells by upregulating iNOS and/or Arg-1 and releasing molecules including ROS, IL-10, TGF- $\beta$ and PGE2 to promote $e . g$. Treg and regulatory $\mathrm{B}$ cell induction (Ostrand-Rosenberg and Fenselau, 2018; Veglia et al., 2018). At the border of the abscesses, $\mathrm{Ly}^{6} \mathrm{C}^{+}$monocytes simultaneously expressing iNOS and Arg-1 were identified, a feature observed only for monocytic MDSCs (Damuzzo et al., 2015). Interestingly, to the best of the authors' knowledge, monocytes being part of an abscess have not been described to date. Furthermore, the $\mathrm{Ly}_{6 \mathrm{G}}{ }^{+}$neutrophils around the SAC expressed Arg-1, not a characteristic of neutrophils per se, but certainly of granulocytic MDSCs (Veglia et al., 2018). Cells positive for Arg-1 protein are present close to SACs, as determined by spatially targeted proteomics (Guiberson et al., 2020). Possibly, the neutrophils around the SAC and within the abscess and the monocytes at the outer rim of the abscess are MDSCs and have suppressive capabilities through Arg-1 or both Arg-1 and iNOS, respectively. This would explain the presence of $\mathrm{FOXP}^{+}$Tregs and M2 macrophages around the abscess. More ex vivo/in vitro investigations are required to assess specifically the immunosuppressive capabilities of these cells. Additionally, it may be that the neutrophils and monocytes together with the M2 macrophages within the abscess initiate encapsulation by secreting high levels of TGF- $\beta$, a pro-fibrotic factor, which upregulates genes involved in extracellular matrix production by fibroblasts and myofibroblasts (Leask and Abraham, 2004). This would also be an interesting future direction of research.

To lower bacterial burden and prevent persistent infection in an FRI, an option would be to target the MDSCs by using an antibody therapy against 
Ly6G, as performed in a murine femoral S. aureus orthopaedic biofilm infection model (Heim et al., 2014). This therapy decreases granulocytic MDSC levels and subsequently decreases bacterial loads in tissue surrounding the implant and the knee joint (Heim et al., 2014). Local application of anti-MDSC therapy may be key for this treatment approach (Tebartz et al., 2015).

Normally, and indeed observed in the noninoculated mice (data not shown), a shift from proinflammatory M1 towards anti-inflammatory M2 macrophages occurs during fracture healing. The first $3 \mathrm{~d}$ after fracture M1 macrophages predominate, whereas by $7 \mathrm{~d}$ M2 macrophages prevail (Schlundt et al., 2018; Wasnik et al., 2018). However, in the present study, inoculated animals had minimal numbers of M1 macrophages and mostly M2 macrophages after $7 \mathrm{~d}$. S. aureus biofilm can skew macrophages to an M2 phenotype in vivo (Thurlow et al., 2011). This might happen because TLR ligands on S. aureus are not accessible for macrophages when $S$. aureus is within a biofilm (Thurlow et al., 2011). A similar process may occur for SACs, which are effectively sealed off from host cells by the fibrin pseudocapsule. When preventing $S$. aureus from growing in a fibrin pseudocapsule by one of the treatment strategies mentioned above, TLR ligands might be more exposed and macrophages might stay in a proinflammatory state instead of being skewed towards an antiinflammatory state. Another interesting treatment option for an FRI is metabolically reprogramming monocytes/macrophages to become proinflammatory with oligomycin nanoparticles, as was shown in a mouse model of S. aureus PJI (Yamada et al., 2020). In addition to changing the metabolic state of monocytes, this therapy also indirectly changed the metabolic state of MDSCs (Yamada et al., 2020).

Taken together, in an $S$. aureus FRI, abscesses contained a central $S$. aureus SAC within a fibrin pseudocapsule. The SAC was surrounded by live neutrophils with only few apoptotic cells, with a mixture of monocytes and M2 macrophages at the border of an abscess. The abscess encapsulation consists of $\alpha \mathrm{SMA}^{+}$myofibroblast, collagen and fibrinogen. Around the abscess, neutrophils, M2 macrophages and Tregs were observed (Fig. 7). The resulting condition in the tissue likely was antiinflammatory and causally related to the persistent S. aureus infection.

\section{Conclusions}

The study provided an in-depth description of the histopathology of an S. aureus FRI as it progressed over time. Fibrin-covered SACs were present within bone marrow abscesses and these abscesses were themselves encapsulated by collagen, fibrinogen and myofibroblasts. Outside the SAC, and inside the abscess margins, the dense accumulation of cells, primarily neutrophils and a few monocytes, were largely vital and showed immunohistochemical markers consistent with granulocytic or monocytic MDSCs, respectively. The bone marrow also contained functionally immunosuppressive MDSCs, M2 macrophages and Tregs, further indicating the local environment to be anti-inflammatory. By better understanding the local inflammatory conditions that lead to the persistence of an infection and the physical features of SACs, it may enable tailored treatment regimens for FRIs.

\section{Acknowledgements}

The authors would like to thank the preclinical facility of the AO Research Institute Davos, Iris Keller, Dr Eamon Sheehy, Jolien Onsea, Aron Keshishian and Susanne Bärtl for their contribution to the animal studies. For help with the (immuno) stains, bone marrow cell and splenocyte isolation as well as imaging, the authors would like to thank Pamela Furlong. Additionally, the authors would like to thank the Innovationsstiftung Graubünden for kindly donating the FACSAria III and Dr Ursula Menzel for her help with sorting the bone marrow cells. This work was supported by AOTrauma grant AR2017_ 05 as part of the Clinical Priority Program on Bone Infection.

\section{References}

Alt V, Lips KS, Henkenbehrens C, Muhrer D, Oliveira Cavalcanti MC, Sommer U, Thormann U, Szalay G, Heiss C, Pavlidis T, Domann E, Schnettler $R$ (2011) A new animal model for implant-related infected non-unions after intramedullary fixation of the tibia in rats with fluorescent in situ hybridization of bacteria in bone infection. Bone 48: 1146-1153.

Bezstarosti H, Van Lieshout EMM, Voskamp LW, Kortram K, Obremskey W, McNally MA, Metsemakers WJ, Verhofstad MHJ (2019) Insights into treatment and outcome of fracture-related infection: a systematic literature review. Arch Orthop Trauma Surg 139: 61-72.

Bjerketorp J, Jacobsson K, Frykberg L (2004) The von Willebrand factor-binding protein (vWbp) of Staphylococcus aureus is a coagulase. FEMS Microbiol Lett 234: 309-314.

Bose D, Kugan R, Stubbs D, McNally M (2015) Management of infected nonunion of the long bones by a multidisciplinary team. Bone Joint J 97-b: 814817.

Brandt SL, Putnam NE, Cassat JE, Serezani CH (2018) Innate immunity to Staphylococcus aureus: evolving paradigms in soft tissue and invasive infections. J Immunol 200: 3871-3880.

Bronte V, Brandau S, Chen SH, Colombo MP, Frey AB, Greten TF, Mandruzzato S, Murray PJ, Ochoa 
A, Ostrand-Rosenberg S, Rodriguez PC, Sica A, Umansky V, Vonderheide RH, Gabrilovich DI (2016) Recommendations for myeloid-derived suppressor cell nomenclature and characterization standards. Nat Commun 7: 12150. DOI: 10.1038/ncomms12150.

Brown JH, Brenn LA (1931) A method for the differential staining of Gram positive and Gram negative bacteria in tissue sections. Bulletin of the John Hopkins XLVIII: 69-73.

Chavakis T, Wiechmann K, Preissner KT, Herrmann M (2005) Staphylococcus aureus interactions with the endothelium: the role of bacterial "secretable expanded repertoire adhesive molecules" (SERAM) in disturbing host defense systems. Thromb Haemost 94: 278-285.

Cheng AG, DeDent AC, Schneewind O, Missiakas D (2011) A play in four acts: Staphylococcus aureus abscess formation. Trends Microbiol 19: 225-232.

Cheng AG, Kim HK, Burts ML, Krausz T, Schneewind O, Missiakas DM (2009) Genetic requirements for Staphylococcus aureus abscess formation and persistence in host tissues. FASEB J 23: 3393-3404.

Cheng AG, McAdow M, Kim HK, Bae T, Missiakas DM, Schneewind O (2010) Contribution of coagulases towards Staphylococcus aureus disease and protective immunity. PLoS Pathog 6: e1001036. DOI: 10.1371/ journal.ppat.1001036.

Dąbrowska D, Jabłońska E, Iwaniuk A, Garley M (2019) Many ways-one destination: different types of neutrophils death. Int Rev Immunol 38: 18-32.

Damuzzo V, Pinton L, Desantis G, Solito S, Marigo I, Bronte V, Mandruzzato S (2015) Complexity and challenges in defining myeloid-derived suppressor cells. Cytometry B Clin Cytom 88: 77-91.

Farnsworth CW, Schott EM, Jensen SE, Zukoski J, Benvie AM, Refaai MA, Kates SL, Schwarz EM, Zuscik MJ, Gill SR, Mooney RA (2017) Adaptive upregulation of clumping factor A (ClfA) by Staphylococcus aureus in the obese, type 2 diabetic host mediates increased virulence. Infect Immun 85: e01005-16. DOI: 10.1128/IAI.01005-16.

Foster TJ, Geoghegan JA, Ganesh VK, Hook M (2014) Adhesion, invasion and evasion: the many functions of the surface proteins of Staphylococcus aureus. Nat Rev Microbiol 12: 49-62.

Friedrich R, Panizzi P, Fuentes-Prior P, Richter K, Verhamme I, Anderson PJ, Kawabata S, Huber $\mathrm{R}$, Bode W, Bock PE (2003) Staphylocoagulase is a prototype for the mechanism of cofactor-induced zymogen activation. Nature 425: 535-539.

Guiberson ER, Weiss A, Ryan DJ, Monteith AJ, Sharman K, Gutierrez DB, Perry WJ, Caprioli RM, Skaar EP, Spraggins JM (2020) Spatially targeted proteomics of the host-pathogen interface during staphylococcal abscess formation. ACS Infect Dis 7: 101-113.

Heim CE, Vidlak D, Kielian T (2015a) Interleukin-10 production by myeloid-derived suppressor cells contributes to bacterial persistence during Staphylococcus aureus orthopedic biofilm infection. J Leukoc Biol 98: 1003-1013.

Heim CE, Vidlak D, Odvody J, Hartman CW, Garvin KL, Kielian T (2018) Human prosthetic joint infections are associated with myeloid-derived suppressor cells (MDSCs): implications for infection persistence. J Orthop Res 36: 1605-1613.

Heim CE, Vidlak D, Scherr TD, Hartman CW, Garvin KL, Kielian T (2015b) IL-12 promotes myeloidderived suppressor cell recruitment and bacterial persistence during Staphylococcus aureus orthopedic implant infection. J Immunol 194: 3861-3872.

Heim CE, Vidlak D, Scherr TD, Kozel JA, Holzapfel M, Muirhead DE, Kielian T (2014) Myeloidderived suppressor cells contribute to Staphylococcus aureus orthopedic biofilm infection. J Immunol 192: 3778-3792.

Hofstee MI, Muthukrishnan G, Atkins GJ, Riool M, Thompson K, Morgenstern M, Stoddart MJ, Richards RG, Zaat SAJ, Moriarty TF (2020a) Current concepts of osteomyelitis: from pathologic mechanisms to advanced research methods. Am J Pathol 190: 11511163.

Hofstee MI, Riool M, Terjajevs I, Thompson K, Stoddart MJ, Richards RG, Zaat SAJ, Moriarty TF (2020b) Three-dimensional in vitro Staphylococcus aureus abscess communities display antibiotic tolerance and protection from neutrophil clearance. Infect Immun 88: e00293-20. DOI: 10.1128/IAI.0029320.

Huh J, Stinner DJ, Burns TC, Hsu JR (2011) Infectious complications and soft tissue injury contribute to late amputation after severe lower extremity trauma. J Trauma 71: S47-51.

Kanakaris N, Gudipati S, Tosounidis T, Harwood P, Britten S, Giannoudis PV (2014) The treatment of intramedullary osteomyelitis of the femur and tibia using the reamer-irrigator-aspirator system and antibiotic cement rods. Bone Joint J 96-b: 783-788.

Klosterhalfen B, Peters KM, Tons C, Hauptmann S, Klein CL, Kirkpatrick CJ (1996) Local and systemic inflammatory mediator release in patients with acute and chronic posttraumatic osteomyelitis. J Trauma 40: 372-378.

Kobayashi SD, Malachowa N, DeLeo FR (2015) Pathogenesis of Staphylococcus aureus abscesses. Am J Pathol 185: 1518-1527.

Leask A, Abraham DJ (2004) TGF-beta signaling and the fibrotic response. Faseb j 18: 816-827.

Lendrum AC, Fraser DS, Slidders W, Henderson R (1962) Studies on the character and staining of fibrin. J Clin Pathol 15: 401-413.

Masters EA, Trombetta RP, de Mesy Bentley KL, Boyce BF, Gill AL, Gill SR, Nishitani K, Ishikawa M, Morita Y, Ito H, Bello-Irizarry SN, Ninomiya M, Brodell JD Jr, Lee CC, Hao SP, Oh I, Xie C, Awad HA, Daiss JL, Owen JR, Kates SL, Schwarz EM, Muthukrishnan G (2019) Evolving concepts in bone infection: redefining "biofilm", "acute vs. chronic osteomyelitis", "the immune proteome" and "local 
antibiotic therapy". Bone Res 7: 20. DOI: 10.1038/ s41413-019-0061-z.

McAdow M, Kim HK, Dedent AC, Hendrickx AP, Schneewind O, Missiakas DM (2011) Preventing staphylococcus aureus sepsis through the inhibition of its agglutination in blood. PLoS Pathog 7: e1002307. DOI: 10.1371/journal.ppat.1002307.

Metsemakers WJ, Kuehl R, Moriarty TF, Richards RG, Verhofstad MHJ, Borens O, Kates S, Morgenstern $M$ (2016) Infection after fracture fixation: current surgical and microbiological concepts. Injury 49: 511-522.

Morgenstern M, Kuehl R, Zalavras CG, McNally M, Zimmerli W, Burch MA, Vandendriessche T, Obremskey WT, Verhofstad MHJ, Metsemakers WJ (2021) The influence of duration of infection on outcome of debridement and implant retention in fracture-related infection. Bone Joint J 103-b: 213-221.

Moriarty TF, Campoccia D, Nees SK, Boure LP, Richards RG (2010) In vivo evaluation of the effect of intramedullary nail microtopography on the development of local infection in rabbits. Int J Artif Organs 33: 667-675.

Nicolás-Ávila J, Adrover JM, Hidalgo A (2017) Neutrophils in homeostasis, immunity, and cancer. immunity 46: 15-28.

Ochsner PE, Hailemariam S (2006) Histology of osteosynthesis associated bone infection. Injury 37 S49-58.

Ostrand-Rosenberg S, Fenselau C (2018) Myeloidderived suppressor cells: immune-suppressive cells that impair antitumor immunity and are sculpted by their environment. J Immunol 200: 422-431.

Peng KT, Hsieh CC, Huang TY, Chen PC, Shih HN, Lee MS, Chang PJ (2017) Staphylococcus aureus biofilm elicits the expansion, activation and polarization of myeloid-derived suppressor cells in vivo and in vitro. PLoS One 12: e0183271. DOI: 10.1371/journal. pone. 0183271.

RauchS, DeDent AC, Kim HK, Bubeck Wardenburg J, Missiakas DM, Schneewind O (2012) Abscess formation and alpha-hemolysin induced toxicity in a mouse model of Staphylococcus aureus peritoneal infection. Infect Immun 80: 3721-3732.

Schlundt C, El Khassawna T, Serra A, Dienelt A, Wendler S, Schell H, van Rooijen N, Radbruch A, Lucius R, Hartmann S, Duda GN, Schmidt-Bleek K (2018) Macrophages in bone fracture healing: their essential role in endochondral ossification. Bone 106: 78-89.

Tebartz C, Horst SA, Sparwasser T, Huehn J, Beineke A, Peters G, Medina E (2015) A major role for myeloid-derived suppressor cells and a minor role for regulatory $\mathrm{T}$ cells in immunosuppression during Staphylococcus aureus infection. J Immunol 194: 11001111.

Thomer L, Emolo C, Thammavongsa V, Kim HK, McAdow ME, Yu W, Kieffer M, Schneewind O, Missiakas D (2016a) Antibodies against a secreted product of Staphylococcus aureus trigger phagocytic killing. J Exp Med 213: 293-301.
Thomer L, Schneewind O, Missiakas D (2016b) Pathogenesis of Staphylococcus aureus bloodstream infections. Annu Rev Pathol 11: 343-364.

Thurlow LR, Hanke ML, Fritz T, Angle A, Aldrich A, Williams SH, Engebretsen IL, Bayles KW, Horswill AR, Kielian T (2011) Staphylococcus aureus biofilms prevent macrophage phagocytosis and attenuate inflammation in vivo. J Immunol 186: 6585-6596.

Tiemann A, Hofmann GO, Krukemeyer MG, Krenn V, Langwald S (2014) Histopathological osteomyelitis evaluation score (HOES) - an innovative approach to histopathological diagnostics and scoring of osteomyelitis. GMS Interdiscip Plast Reconstr Surg DGPW 3: Doc08. DOI: 10.3205/iprs000049.

Trampuz A, Zimmerli W (2006) Diagnosis and treatment of infections associated with fracturefixation devices. Injury 37 Suppl 2: S59-66.

Vanassche T, Verhaegen J, Peetermans WE, J VANR, Cheng A, Schneewind O, Hoylaerts MF, Verhamme P (2011) Inhibition of staphylothrombin by dabigatran reduces Staphylococcus aureus virulence. J Thromb Haemost 9: 2436-2446.

Veglia F, Perego M, Gabrilovich D (2018) Myeloidderived suppressor cells coming of age. Nat Immunol 19: 108-119.

Wasnik S, Rundle $\mathrm{CH}$, Baylink DJ, Yazdi MS, Carreon EE, Xu Y, Qin X, Lau KW, Tang X (2018) 1,25-Dihydroxyvitamin D suppresses M1 macrophages and promotes M2 differentiation at bone injury sites. JCI Insight 3: e98773. DOI: 10.1172/ jci.insight.98773.

Yamada KJ, Heim CE, Xi X, Attri KS, Wang D, Zhang W, Singh PK, Bronich TK, Kielian T (2020) Monocyte metabolic reprogramming promotes pro-inflammatory activity and Staphylococcus aureus biofilm clearance. PLoS Pathog 16: e1008354. DOI: 10.1371/journal.ppat.1008354.

\section{Discussion with Reviewers}

Robert Mooney: Having concluded that the present mouse FRI model reflected an acute infection, how might the model be modified to represent a chronic infection?

Authors: The mouse FRI model used indeed did not represent a chronic infection but mice had an initial acute infection that progressed to a chronically florid/ active infection after $28 \mathrm{~d}$. S. aureus predominantly causes relatively acute infections in human patients and chronic infections are more common with coagulase-negative staphylococci. Nevertheless, chronic $S$. aureus infections do occur, for example after failed revisions or suppressive long term antibiotic therapy. The reason that the present mouse FRI model did not represent a chronic infection might be due to a time-related issue. An indication for this is that the encapsulation around the abscesses was still relatively immature at $28 \mathrm{~d}$. If later time points were chosen, the entire abscess structure might have developed and become more mature. 
By this time, there may also be more lymphocyte and macrophage infiltration, characteristic of a chronic infection rather than a neutrophil infiltration. However, it is important to note that there is a risk that longer observation periods would likely lead to continued osteolysis, leading eventually to a failure of the implant and the need to exclude the animal. Increased implant failure rates have been observed in past studies as the observation period increases. Thus, this infection model may be more suited to study effects at earlier timepoints. One possibility to allow for extended observation periods may be to administer a low dose of suppressive antibiotics, to maintain the infection in a relatively controlled state and to allow the encapsulation to mature and the host defences to organise. However, at the present time, it is unknown how such antibiotic therapy may change the course of the infection, but this would be the most appropriate means to begin developing a chronic infection model.

Reviewer: In the discussion, the authors state the following: "A similar approach may be applied for an FRI but given that fibrin is also important for fracture healing, targeting only bacterial proteins involved in the conversion of fibrinogen into fibrin would be preferred". The authors only briefly discussed a very important issue. Targeting fibrin would negatively influence fracture healing. Do the authors have other targets in mind?

Authors: Yes, we indeed do have other targets in mind. Instead of targeting the conversion of fibrinogen into fibrin with a generic thrombin inhibitor that inhibits both the host thrombin as well as staphylothrombin, a more desired approach would be to target staphylothrombin specifically. Staphylothrombin is a combination of either Coa or vWbp with the host prothrombin, making the proenzyme active. Thomer et al. (2016a) have shown that the highly conserved R-domain of Coa can be targeted with an antibody causing less fibrin-mediated aggregation of $S$. aureus and a drop in $S$. aureus infection rates. A similar approach might be used for $\mathrm{vWbp}$. Besides inhibiting the conversion of fibrinogen into fibrin by $S$. aureus proteins, an option would be to block $S$. aureus binding to fibrinogen/fibrin by for example using an anti-ClfA antibody or to block both the binding of fibrinogen/fibrin and staphylothrombin. When $S$. aureus is not able to aggregate and surround itself with fibrin, immune cells may have a chance in clearing the bacteria, which might subsequently prevent the expansion of immunosuppressive MDSCs and anti-inflammatory macrophages. Furthermore, an option would be to directly prevent the expansion of immunosuppressive MDSCs and anti-inflammatory macrophages by, for example, using a local antibody therapy against MDSCs or by metabolically reprogramming monocytes/ macrophages to become proinflammatory with oligomycin nanoparticles, respectively.

Editor's note: The Guest Editor responsible for this paper was Henny Van der Mei. 